This item was submitted to Loughborough's Research Repository by the author.

Items in Figshare are protected by copyright, with all rights reserved, unless otherwise indicated.

\title{
Progress in low-field benchtop NMR spectroscopy in chemical and biochemical analysis
}

PLEASE CITE THE PUBLISHED VERSION

https://doi.org/10.1016/j.aca.2019.02.026

PUBLISHER

(C) Elsevier BV

VERSION

AM (Accepted Manuscript)

PUBLISHER STATEMENT

This paper was accepted for publication in the journal Analytica Chimica Acta and the definitive published version is available at https://doi.org/10.1016/j.aca.2019.02.026.

LICENCE

CC BY-NC-ND 4.0

\section{REPOSITORY RECORD}

Grootveld, Martin, Benita C. Percival, Miles Gibson, Yasan Osman, Mark Edgar, Marco Molinari, Melissa L. Mather, Federico Casanova, and Philippe B. Wilson. 2019. "Progress in Low-field Benchtop NMR Spectroscopy in Chemical and Biochemical Analysis". figshare. https://hdl.handle.net/2134/37839. 
Analytica Chimica Acta 2019

1 Progress in Low Field Benchtop NMR Spectroscopy:

\section{Chemical and Biochemical Analysis.}

3 Martin Grootveld ${ }^{\ddagger}$, Benita Percival,${ }^{\ddagger}$ Miles Gibson, ${ }^{\ddagger}$ Yasan Osman, ${ }^{\ddagger}$ Mark Edgar, ${ }^{\S}$ Marco Molinari,${ }^{\dagger}$

4 Melissa L. Mather, „Federico Casanoval and Philippe B. Wilson ${ }^{\ddagger} *$

5 Chemistry for Health/Bioanalytical Sciences Research Group, Leicester School of Pharmacy, De

6 Montfort University, Leicester, LE1 9BH, UK

$7 \quad \S$ Department of Chemistry, Loughborough University, Epinal Way, Loughborough, LE11 3TU, UK

$8 \quad$ 'School of Applied Sciences, University of Huddersfield, Queensgate, Huddersfield, HD1 3DH, UK

$9 \|$ Department of Electronic and Electrical Engineering, University of Nottingham, University Park,

10 Nottingham, NG7 2RD, UK

11 "Magritek GmbH, Philipstraße, 8, 52068 Aachen, Germany

$12 *$ Corresponding Author Email: philippe.wilson@dmu.ac.uk

14 Abstract

The employment of spectroscopically-resolved NMR techniques as analytical probes have previously

16 been both prohibitively expensive and logistically challenging in view of the large sizes of high-field

17 facilities. However, with recent advances in the miniaturisation of magnetic resonance technology,

18 low-field, cryogen-free "benchtop" NMR instruments are seeing wider use. Indeed, these miniaturised

19 spectrometers are utilised in areas ranging from food and agricultural analyses, through to human

20 biofluid assays and disease monitoring. Therefore, it is both intrinsically timely and important to

21 highlight current applications of this analytical strategy, and also provide an outlook for the future,

22 where this approach may be applied to a wider range of analytical problems, both qualitatively and

23 quantitatively.

24 Keywords 
Analytica Chimica Acta 2019

1 Compact NMR, mobile NMR, benchtop NMR, biofluid analysis

2

3 Abbreviations

$4 \quad 1 \mathrm{D}$

One dimensional

5

2D Two dimensional

6 bNMR

Benchtop nuclear magnetic resonance

$7 \mathrm{COSY}$

Correlation spectroscopy

$8 \quad \mathrm{CPMG}$

Carr-Purcell-Meiboom-Gill

9 DEPT

Distortionless enhancement by polarization transfer

10 DOSY

Diffusion ordered spectroscopy

11 DNP

Dynamic nuclear polarisation

12 FID

Free induction decay

$13 \mathrm{GC}$

Gas chromatography

14 HETCOR Heteronuclear correlation spectroscopy

$15 \mathrm{HF}$

High-field

16 HMBC

Heteronuclear multiple bond correlation

$17 \quad$ HP

Hyperpolarisation

18 HPLC

High performance liquid chromatography

19 HSQC

Heteronuclear single quantum correlation

$20 \quad$ IR

Infra-red

21

LF

Low-field 
Analytica Chimica Acta 2019

1 LLOD Lower limit of detection

2 LLOQ Lower limit of quantification

3 MAS Magic angle spinning

$4 \quad \mathrm{MHz} \quad$ Megahertz

5 MOF Metal-organic framework

6 MRI Magnetic resonance imaging

7 NMR Nuclear magnetic resonance

8 NOE Nuclear Overhauser effect

9 NP Nanoparticle

10 NUS Non-uniform sampling

11 NV Nitrogen vacancy

12 PAT Process analytical test

13 PCA Principal component analysis

14 PLS Partial least squares

15 QC Quality control

16 SABRE Signal amplification reversible exchange

17 SNR Signal-to-noise ratio

$18 \mathrm{~T} \quad$ Tesla

19 TOCSY Total correlated spectroscopy

20 TSP (Trimethylsilyl)[ $-2,2,3,3-\mathrm{d} 4]$ propionic acid /sodium salt

21 UV Ultraviolet 


\section{Contents}

4
1. Introduction

2. Experimental developments

3. Applications in materials chemistry

4. Low-field NMR spectroscopy in food and agricultural chemistry

5. Reaction monitoring and chemical transformations

6. Structural and forensic chemistry
References. 46

\section{Introduction}

Nuclear magnetic resonance (NMR) spectroscopy has been widely applied in chemical and biochemical analysis for decades, with high-resolution instruments now possessing the necessary sensitivity to successfully probe large biological structures such as proteins [1]. Advances in the technology used to develop the very large, superconducting magnets employed for these highresolution studies has led to successively increased spectral resolution, developments which have allowed us to consider even larger chemical systems. However, with these improvements in sensitivity and resolution come larger and more robust instruments requiring dedicated laboratories, with high purchase and operating costs, particularly those involving cryofluid replenishment for the latter; one major limitation of this approach is that such facilities are inherently inappropriate for field or benchtop studies [2,3], whilst being less sensitive to both charge effects in polyelectrolyte solutions and conducting samples. Indeed, although the advent of cryogenic probes has resulted in marked increases in sensitivity when compared to earlier probeheads, this is only realised in practice if samples are in fact electrically insulating, such as in organic solvents. Cryogenic probes function by 


\section{Analytica Chimica Acta 2019}

1 cooling the RF receiver coils to temperatures below $30 \mathrm{~K}$. This lowers the resistance of the coils,

2 thereby increasing signal amplitude and reducing thermal noise levels. The combination of these

3 effects results in an increase in the sensitivity, which is monitored by signal-to-noise ratio (SNR).

4 Conversely, conductive samples will therefore supplement the resistance to the RF receiver coil, and

5 hence decrease SNR values.

6 Commercial benchtop NMR spectrometers are most notably available from Thermofisher, Nanalysis,

7 Oxford Instruments, and Magritek, currently predominantly operating at $60 \mathrm{MHz}(1.41 \mathrm{Tesla}(\mathrm{T}))$ and

$8 \quad 80 \mathrm{MHz}$ (1.88 T) operating frequencies, with $190 \mathrm{MHz}(4.45 \mathrm{~T})$ Halbach-enhanced designs being

9 envisaged,[4] and $212 \mathrm{MHz}(5 \mathrm{~T})$ versions possible [5]. In very early experiments, NMR spectra were

10 recorded at only 40 or $60 \mathrm{MHz}$ operating frequencies. However, current conventional high-field

11 spectrometer studies take place with magnets at $400 \mathrm{MHz}$ or above, and therefore it is timely to

12 highlight the advantages of low-field NMR techniques [6].

Large NMR instruments based on permanent magnets and electromagnets were commonplace until the 1970s, with the emergence of superconducting instruments; however, these were both expensive and attained similar sizes to those of the superconducting instruments we see today. In order to generate stable, sufficiently strong magnetic fields in instruments of manageable size for traditional laboratories and benchtop work, small permanent magnets weighing approximately 500 grams, and with homogeneous magnetic fields, were reported based on designs by Halbach [7] (Figure 1). Considering that permanent magnets currently generate fields of up to $2 \mathrm{~T}$, and that field strength remains constant when magnet volume is scaled down, the observed sensitivity decrease would approximate to a factor of 3 orders of magnitude when compared to the $7 \mathrm{~T}$ fields of instruments with superconducting magnets [8]. Indeed, the construction and availability of these magnets, incorporated within user-friendly, cryogen-free, low-field (LF) benchtop instruments, has led to an abundance of recent applications of this technology [9]. 


\section{Analytica Chimica Acta 2019}

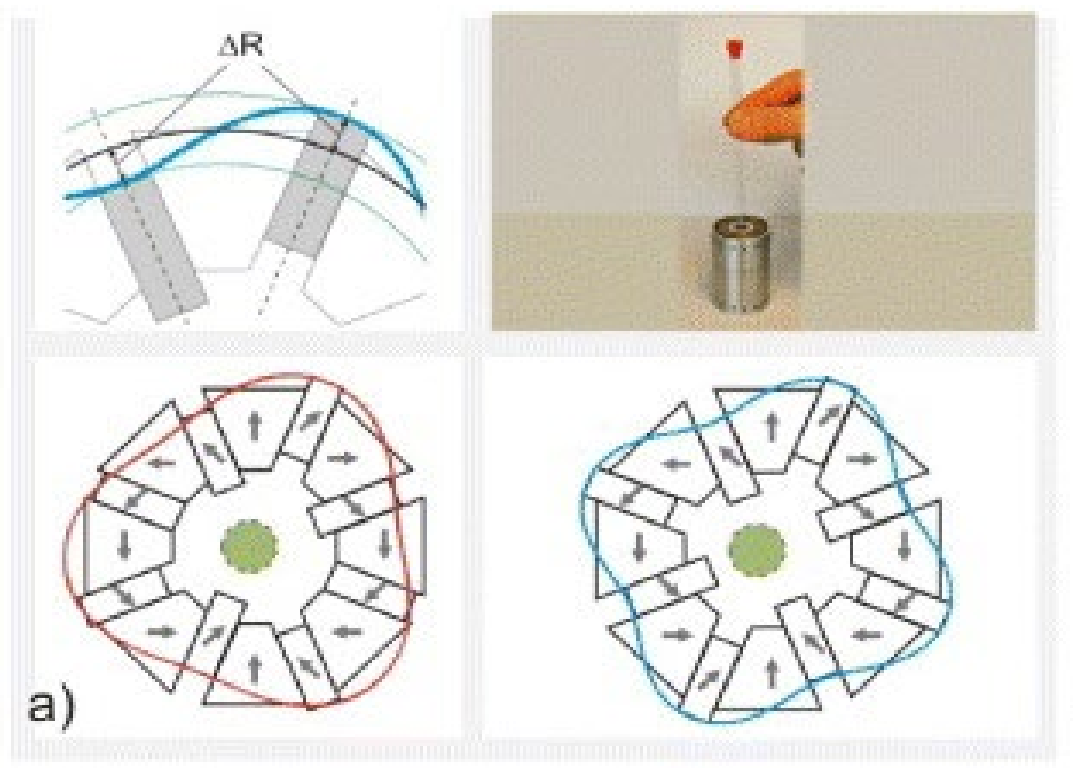

2 Figure 1. Diagram from Ref. [10], originally published open access in the New Journal of Physics,

3 IOP. NMR magnets from permanent magnet materials. (a) Halbach magnet constructed from trapezoidal magnet blocks with gaps between them in which magnetic plates are moved in and out in order to shim the field, where $\Delta \mathrm{R}$ represents the shimming distance. Typical field strengths are $0.5 \mathrm{~T}$ for imaging, and $1.0 \mathrm{~T}$ for spectroscopy.

8 Furthermore, with NMR spectroscopy representing one of the most widely used techniques in analytical chemistry [11], the prospects are promising for small benchtop instruments to be applied in areas ranging from medicine and clinical science, through to food and environmental sciences.

11 Herein, we present a recent overview of the area of LF benchtop NMR spectroscopy (bNMR), and provide a perspective on future applications. We also provide an update on the very recent novel employment of LF bNMR technologies to the NMR-linked metabolomics area, and here we showcase the applications of this technique to the diagnosis and metabolic monitoring of type 2 diabetes [12]. A more extensive description of the fundamental principles of compact LF NMR can be found here [13$15]$. 


\section{Analytica Chimica Acta 2019}

\section{Experimental developments}

Although NMR is ubiquitous in chemical analysis, it is less sensitive than alternative techniques [16]. As such, it is important to determine the SNR for analytes in NMR measurements. Indeed, the SNR scales to the square of the static magnetic field, $B_{0}$, and this has led to significant investments in developing increasingly high-field magnets. However, with the relatively small magnetic fields produced in bNMR instruments, obtaining SNRs allowing for detection $(\mathrm{SNR} \geq 3)$ and quantification (SNR $\geq 10$ ) purposes can become challenging [17]. Hence, both sensitivity and selectivity barriers must be overcome for a number of bNMR applications.

The limit of detection (LOD) concentration values of LF instruments has long been described as an important hurdle to surmount in order for the technique to have wider applications [18]. Indeed, a number of methods have been developed to enhance the spin effects observed in NMR for LF applications, amongst others [19]. Hyperpolarisation (HP) of nuclear spins greatly enhances signal intensities, with the potential to significantly expand the scope of both spectroscopic NMR and MRI systems, as well as sensing technologies [20]. The most well-known derivative of this technique, dynamic nuclear polarisation (DNP), engenders several hundred-fold increases in sensitivity for solid material analytes [21]. Moreover, in solution, DNP has been shown to increase sensitivity up to ten thousand times under standard conditions, opening up a variety of applications for lower frequency spectrometers [19].

DNP in compact, LF-NMR analysis has been applied to successfully study numerous processes such as lactate dehydrogenase activity in prostate carcinomas through hyperpolarisation of $\left[1-{ }^{13} \mathrm{C}\right]$ pyruvate [22], as well as mouse brain metabolism [23], together with molecular dynamics in block copolymers [24]. In addition to DNP, signal amplification by reversible exchange (SABRE) is considered a rapid and efficient method of NMR hyperpolarisation that can enhance the sensitivity of proton and heteronuclear experiments [25]. SABRE does not require a hydrogenation reaction, and can occur in the liquid state under standard conditions with relatively cheap equipment (Figure 2); a transition 
1 metal ion catalyst is employed to establish the contact between para- $\mathrm{H}_{2}$, which is the polarisation

2 source, and nuclei of interest [26].

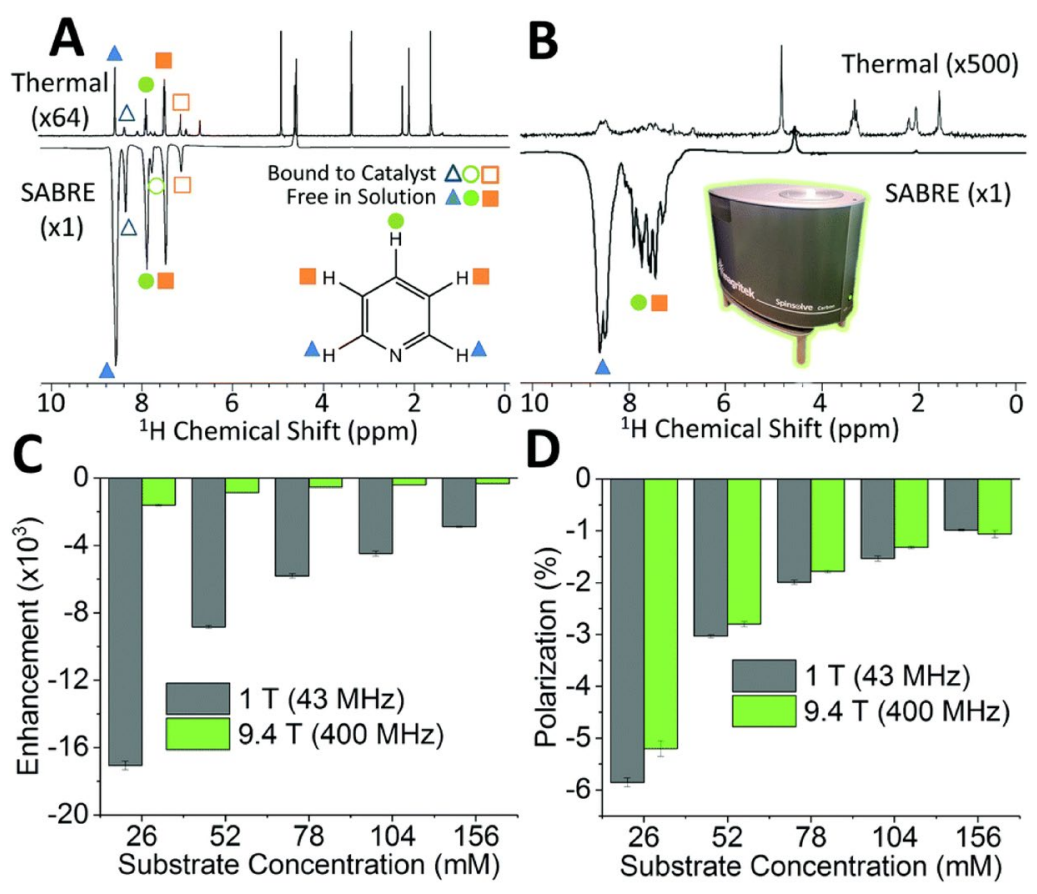

Figure 2. Reproduced from Ref [27] with permission from The Royal Society of Chemistry.

5 Comparison of thermally-polarized (top) and SABRE hyperpolarized (bottom) ${ }^{1} \mathrm{H}$ NMR spectra of 52

$6 \mathrm{mM}$ pyridine with $5.2 \mathrm{mM}$ catalyst in methanol- $\mathrm{d}_{4}$ for detection at (A) $9.4 \mathrm{~T}$ and (B) $1.0 \mathrm{~T}$. (C)

7 SABRE enhancement factor, $\varepsilon$, and (D) polarization level, $\mathrm{P}$, for the ortho- resonance (blue triangle)

8 as a function of substrate concentration with NMR detection at $1.0 \mathrm{~T}$ (grey) and $9.4 \mathrm{~T}$ (green). Error

9 bars represent the standard deviation across 5 repeat measurements.

11 A heteronuclear alternative, described as SABRE-SHEATH, enables alignment transfer to

12 heteronuclei, and has been reported to successfully apply to the hyperpolarisation of ${ }^{15} \mathrm{~N}$. It appears that ${ }^{15} \mathrm{~N}$-SABRE may be effectively applied to a wider range of substrates than its ${ }^{1} \mathrm{H}$ equivalent, thereby generalising the technique. Additionally, $T_{1}$ values for ${ }^{15} \mathrm{~N}$ are prolonged up to 12 minutes, allowing for increased levels of hyperpolarisation; this development is also appealing for lengthened molecular imaging times, further opening up the field of hyperpolarised biomolecular imaging [28]. 


\section{Analytica Chimica Acta 2019}

1 More recently, brute force HP has appeared as an alternative to DNP. It uses only two components in order to hyperpolarise a molecule, specifically those involving a low temperature and high magnetic field, and thereby not requiring free radical, microwave excitation or co-solvent processes necessary for variants of DNP. Relying instead on the Boltzmann law, brute force hyperpolarisation also does not require the metal ion catalysts inherent in parahydrogen hyperpolarisation techniques. Recently reported applications of brute force hyperpolarisation NMR/MRI have reached thousand- fold gains in sensitivity within the low-frequency bNMR range [29]. The simplicity of this low temperature, high magnetic field approach to hyperpolarisation also opens up possibilities for the transport of HP nuclei. Indeed, with slowly relaxing nuclei of low gyromagnetic ratios, it has been suggested that $T_{I}\left({ }^{13} \mathrm{C}\right)$ amounts to approximately 1 hour at $50 \mathrm{~K}$, and 24 hours at $10 \mathrm{~K}$ (or more than ten times the half-life of ${ }^{19} \mathrm{~F}$ used for positron emission tomography imaging). Hence, there is significant scope for this technique to be developed further in order to drastically enhance the sensitivity of LF instruments, which currently struggle somewhat with some analytes present at low concentrations. Indeed, although HP techniques have substantial potential to increase the applicability of these instruments, the current HP strategies described herein suffer from practical issues; dissolution DNP is frequently used in developing contrast agents, but it suffers from a high cost, as well as complex hardware for implementation. Whilst alternative parahydrogen techniques are effective, they are not as widely applicable. Although the SABRE technique is a fast and reversible HP method, it is currently limited to $\mathrm{HP}{ }^{1} \mathrm{H}$ investigations, and therefore future work, most likely to be based on the aforementioned SABRE-SHEATH methodology, will focus on HP transfer to ${ }^{13} \mathrm{C}$ and ${ }^{15} \mathrm{~N}$ nuclei. It has also been suggested that HP techniques will further encompass the applications of two-dimensional (2D) spectra in the short-term [30].

In view of the low operating frequencies and low magnetic fields of bNMR instruments, resonances often significantly overlap, which leads to less valuable and less easily interpretable spectra. Moreover, such adverse overlap is amplified as the magnitudes of coupling constants approach the range of chemical shift dispersion; this further complicates the characterisation of analytes. It has therefore been valuable to apply 2D methods to LF spectra in order to enhance spectral resolution 


\section{Analytica Chimica Acta 2019}

through expanding the resonances over a 2D spectral map, whilst affecting sensitivity. Furthermore, a number of pulse sequence variants have recently been developed in order to generate these enhanced 2D spectra [31]. However, these advantages offered by 2D LF NMR analyses are deleteriously associated with long acquisition times, which somewhat reduce the viability of this technique for high-throughput screening or reaction monitoring purposes. Until recently, hardware restricted the application of ultra-fast 2D NMR analysis at LF. Fortunately, however, dedicated high-performance gradient coils are becoming available for incorporation into LF bNMR instruments, with the first application successfully achieved on a $43 \mathrm{MHz}$ facility [32]. As such, robust methodologies in ultrafast NMR have been developed at LF, and these rely on substitution of the $t_{l}$ period by a spatially-dependent period of evolution. Within a single scan, the sample is therefore conceptually separated into partitions subject to different periods of evolution, which depend on their relative spectral frequencies.

The congestion in ${ }^{1} \mathrm{H}$ NMR spectra at LF arises mainly from overlapping multiplets, with a standard ${ }^{3} J_{\mathrm{H}-\mathrm{H}}$ coupling of $20 \mathrm{~Hz}$ for a trans-alkene occupying $0.50 \mathrm{ppm}$ at a $40 \mathrm{MHz}$ operating frequency. COSY experiments can help to locate coupling pathways in congested parts of the NMR spectrum, with selective-TOCSY approaches offering significant advantages by extracting a specific coupled spin-system from a complex mixture. The pure-shift method can collapse a multiplet from a ${ }^{1} \mathrm{H}$ NMR spectrum to yield a singlet, which offers significant advantages since overlap in spectra acquired is vastly reduced.

Commonly-used resonance peak integration methods have been shown to suffer from certain deficiencies, particularly when applied to LF bNMR data [33]. Specifically, these are limited in their capability to resolve overlapping signals, and are inherently affected by noise, leading to the development of several novel methods of corrections and FID data analysis [34]. A recently reported Bayesian model involving lineshape and baseline corrections has been shown to account for chemical shift, relaxation, lineshape imperfections and phasing, as well as baseline distortions. This model was validated against simulation and experiment, using simple molecules for characterisation, and showed an absolute accuracy of at least $0.01 \mathrm{~mol} / \mathrm{mol}$ (in terms of mole fractions) for high SNR values of 


\section{Analytica Chimica Acta 2019}

$6 \quad S N R=10 \log \left(\frac{P_{S}}{P_{n}}\right)$ ratio properties.

more than $40 \mathrm{~dB}$. In the context of this model, SNR is defined in Equation 1, where $P_{s}$ and $P_{\mathrm{n}}$ are represented as the energies of the resonance of interest, and the background noise, respectively. $P_{\mathrm{s}}$ is obtained from the model-based method, whilst $P_{n}$ can be derived from the Gaussian noise, or alternatively the product of the total number of samples and the estimated noise variance, or from direct measurement of signal-free regions in the spectrum.

For values of SNR less than $20 \mathrm{~dB}$, accuracy was reported as $0.05-0.10 \mathrm{~mol} / \mathrm{mol}$. This has significant implications for LF compact instruments which suffer from higher noise than their high-field counterparts; however the simplicity of the test systems involved in the study have been highlighted, and additional testing on more complex, inhomogeneous systems has been suggested [33]. Furthermore, additional work has focused on corrections to phase and set the baseline for signals through complex optimisation strategies. This method applies these corrections simultaneously and in an automated fashion, with no requirement for manual input, and has been reported to provide more interpretable results than those arising from other techniques. Implementing a Pareto optimisation to the concerted automated correction, as well as Whittaker smoothing to correct the baseline, this novel approach was demonstrated on both high-field and bNMR spectroscopic data, suggesting improvements in interpretation, particularly for spectra obtained from compact instruments [35].

Recently, lanthanide shift reagents have been used to increase the frequency dispersion in bNMR spectra through their abilities to form metal ion complexes, chelate or otherwise, with target analytes. Whilst being frequently applied to high-field techniques, the implementation of lanthanide shift reagents on a bNMR spectrometer through $1 \mathrm{D}{ }^{1} \mathrm{H}$ and ${ }^{19} \mathrm{~F}$, and $2 \mathrm{D}{ }^{19} \mathrm{~F}$, has only recently been reported [36]. This presents an additional approach to the uncrowding of LF NMR spectra, whilst effects on line-broadening must also be taken into account; high concentrations of lanthanide complexes tend to induce increased bandwidths in spectra in view of decreases in $T_{2}$ values. This effect is less pronounced for $\mathrm{Eu}(\mathrm{III})$ and $\operatorname{Pr}(\mathrm{III})$ complexes, a consequence of their inefficient nuclear spin-lattice 


\section{Analytica Chimica Acta 2019}

1 Methods to improve acquisition efficiency have significant appeal to bNMR systems, and one robust and widely applicable method is non-uniform sampling (NUS). This overcomes the inefficient sampling method traditionally used for acquiring 2D NMR data, and allows equivalent quality data to be recorded in just $25 \%$ of the time usually required to acquire a spectrum [37].

Materials such as foods, cosmetics, healthcare and oral healthcare products, polymers and further chemical substances can be explored by relaxation measurements, for example determinations of the solid fat contents of dairy products may be performed on MiniSpec benchtop NMR analysers (Bruker, Billerica, Massachusetts, USA) via the differing relaxation behaviours of the solid and liquid components of such non-solution-state matrices [38]. Such facilities have been available and operational since the 1970 's, and are readily applicable to the detection and quantification of ${ }^{1} \mathrm{H},{ }^{19} \mathrm{~F}$ and further NMR-active nuclei in a range of materials and other predominantly solid-phase products, for example, determinations of the total fluorine contents of toothpastes [39]. However, since this review is focussed on spectroscopic applications of LF bNMR instruments only, such relaxometric analyses will not be discussed further here.

\section{Applications in materials chemistry}

Materials and their interfaces have widely been studied by NMR/MRI [40]. More recently, however, the availability and relatively low cost of LF benchtop instruments has led to a plethora of applications in this field [13]. These include studies of rubber [3], nanoparticles [41], and porous materials [42], with relaxation studies of solid-state materials and metal-organic frameworks (MOFs) able to explore the pore-space of MOFs, and the determination of adsorption characteristics [43].

LF NMR has been applied to the quantification of differences between varieties of styrene-butadiene rubber. Individual components in the system, which differed between sites of origin, were detectable with a benchtop instrument, on which 108 samples were analysed in ${ }^{1} \mathrm{H}$ and ${ }^{13} \mathrm{C}$ NMR experiments performed on a $1.0 \mathrm{~T}$ instrument. Partial least-squares (PLS) regression allowed for a quality control (QC) methodology to be developed for rubber varieties and their origins, and/or relative qualities. 
signals in polymerised rubber systems, suggesting a defined role for LF NMR techniques combined

with chemometrics analysis in QC processes for raw rubber quality assessments [3].

3 Additionally, exploiting optical defects in crystals, such as nitrogen vacancy (NV) centres in diamond, can lead to signal enhancement compared to traditional methods of detection and excitation [44].

Indeed, these techniques can also be applied to transfer hyperpolarisation from the $\mathrm{NV}$ to nearby ${ }^{13} \mathrm{C}$

nuclei, leading to significant signal enhancements [45].

Table 1. Benefits, limitations and potential future applications of LF benchtop NMR techniques in the 9 analysis of materials.

\begin{tabular}{|c|c|c|}
\hline Criterion & Comments & $\begin{array}{l}\text { Relevant } \\
\text { References }\end{array}$ \\
\hline $\begin{array}{l}\text { Applicable to a } \\
\text { range of } \\
\text { materials and } \\
\text { conditions }\end{array}$ & $\begin{array}{l}\text { For geological methods, for example, NMR analysis is ideally } \\
\text { performed on a portable instrument; however, a variety of facilities } \\
\text { have been developed for this purpose. More traditional benchtop } \\
\text { devices have been used to characterise materials ranging from } \\
\text { magnetic nanoparticles to rubbers. }\end{array}$ & {$[3,10,41,46]$} \\
\hline $\begin{array}{l}\text { Sample } \\
\text { preparation }\end{array}$ & $\begin{array}{l}\text { Little or no sample preparation is required. No sample preparation } \\
\text { at all is necessary for qualitative (identification) purposes } \\
\text { performed by LF spectrometers not requiring added }{ }^{2} \mathrm{H}_{2} \mathrm{O} \text {, nor for } \\
\text { hand-held portable NMR devices. For the former class of facilities, } \\
\text { in some cases only the direct transference of samples to NMR } \\
\text { tubes is required. }\end{array}$ & {$[2,42]$} \\
\hline Selectivity & $\begin{array}{l}\text { Analytes such as complex polymers may require supplementary } \\
\text { chemometrics techniques to be applied in order for resonances to } \\
\text { be robustly identified within multistep frameworks such as quality } \\
\text { control protocols. LF hand-held instruments rely instead on } \\
\text { indirect secondary measurements. }\end{array}$ & [3] \\
\hline Sensitivity & $\begin{array}{l}\text { Superior to common alternatives for adsorption measurements in } \\
\text { porous materials, such as gravimetric or volumetric analyses in } \\
\text { which secondary effects such as pressure or mass changes are } \\
\text { measured. Appropriate for the measurement of parameters such as } \\
\text { Henry's constant, adsorption capacity, and adsorption separation } \\
\text { factor in microporous materials. Measurement of transverse } \\
\text { relaxivities (inverse } T_{1} \text { and } T_{2} \text { ) of nanoparticles are sensitive to } \\
\text { their aggregation state, and appropriate for quantification } \\
\text { purposes, respectively. }\end{array}$ & {$[41,43]$} \\
\hline Versatility & $\begin{array}{l}\text { A variety of instruments and techniques are applied in view of the } \\
\text { diversity of media in the context of materials amenable to LF } \\
\text { NMR characterisation. Hand-held sensors used in geological } \\
\text { investigations are highly versatile, but with low sensitivity (when } \\
\text { compared to the benchtop LF spectrometers or bespoke solid-state } \\
\text { sensors). }\end{array}$ & {$[15,47]$} \\
\hline Limitations & $\begin{array}{l}\text { Solid-state NMR investigations with benchtop instruments are } \\
\text { limited to diffusion/relaxation studies through time-domain NMR. } \\
\text { The chemical shift is not readily resolved in these inhomogeneous }\end{array}$ & {$[40,41]$} \\
\hline
\end{tabular}




\begin{tabular}{|l|l|l|}
\hline fields. However, it is possible to estimate indirect coupling, & \\
allowing for basic chemical analysis. Magnetic NPs currently also & \\
require characterisation with transmission electron microscopy or & X-ray diffraction, which could support NMR analysis by providing & \\
additional information on relaxation behaviour, quantitative & \\
comparisons or relaxation theories. & \\
\hline
\end{tabular}

\section{Low-field NMR spectroscopy in food and agricultural chemistry}

The availability of compact LF NMR instruments has led to their rapid uptake in the food processing and quality control areas, and the chemical analysis of agents in dietary products have been widely reported [47,48]; recent media coverage of horsemeat product substitutions for beef highlighted identifiable differences in their triacylglycerol contents in ${ }^{1} \mathrm{H}$ NMR spectra acquired on LF instruments [49]. Moreover, the identification and purity of edible oils has generated much public attention with adulterants being found in many commonly-available products. Recent studies on olive oil mixtures suggest an important role for compact, LF NMR instruments for quality control evaluations. Indeed, since pressed hazelnut oil, a common olive oil adulterant, has oleoyl-, linoleoyl-, and linolenoylglycerol contents which differ significantly from those of unadulterated olive oil, this method serves as the basis of adulteration tests for commercial samplings of the latter. It has been possible to use the lineshapes of selected methylene function resonances in order to identify 'fingerprints' for differing samples and mixtures (Figure 3) [50]. More recently, the authentication of edible oils has formed part of a more methodological study to identify appropriate techniques for their NMR characterisation at LF. Experiments were carried out on a $43 \mathrm{MHz}$ instrument, and this study reported that in terms of efficiency, a methodology based on 2D spectra obtained over less than 3 minutes was more efficient than 1D experiments performed on the same samples [51]. This was rationalised in view of the significant resonance overlap in 1D spectra, and the facile discrimination between six edible oils through principal component analysis (PCA) of 2D data. Furthermore, it has 


\section{Analytica Chimica Acta 2019}

1 adulteration through the same method, with a similar procedure being applied in an authenticity and

2 adulteration study of perilla oils distributed in Korea [52], and also for Patchouli essential oil [53].

3 Intriguingly, Grootveld et. al. [54] recently employed LF NMR analysis using a 1.4 T LF benchtop

4 NMR instrument in order to successfully detect 3 major classes of aldehydic lipid oxidation products

5 (i.e. trans-2-alkenals, trans,trans-alka-2,4-dienals, and $n$-alkanals arising from the peroxidation of

6 unsaturated fatty acid sources) in samples of repeatedly-used olive oils employed for deep-frying

7 purposes in a restaurant. Consistent with this observation, frying time-dependent decreases in frying

8 oil polyunsaturated fatty acid contents were also observable with this technique, specifically highly

9 significant thermally-induced decreases in the intensities of their bis-allylic- $\underline{\mathrm{H}}_{2}$ function multiplet

10 resonance $(\delta=2.76 \mathrm{ppm})$.

11

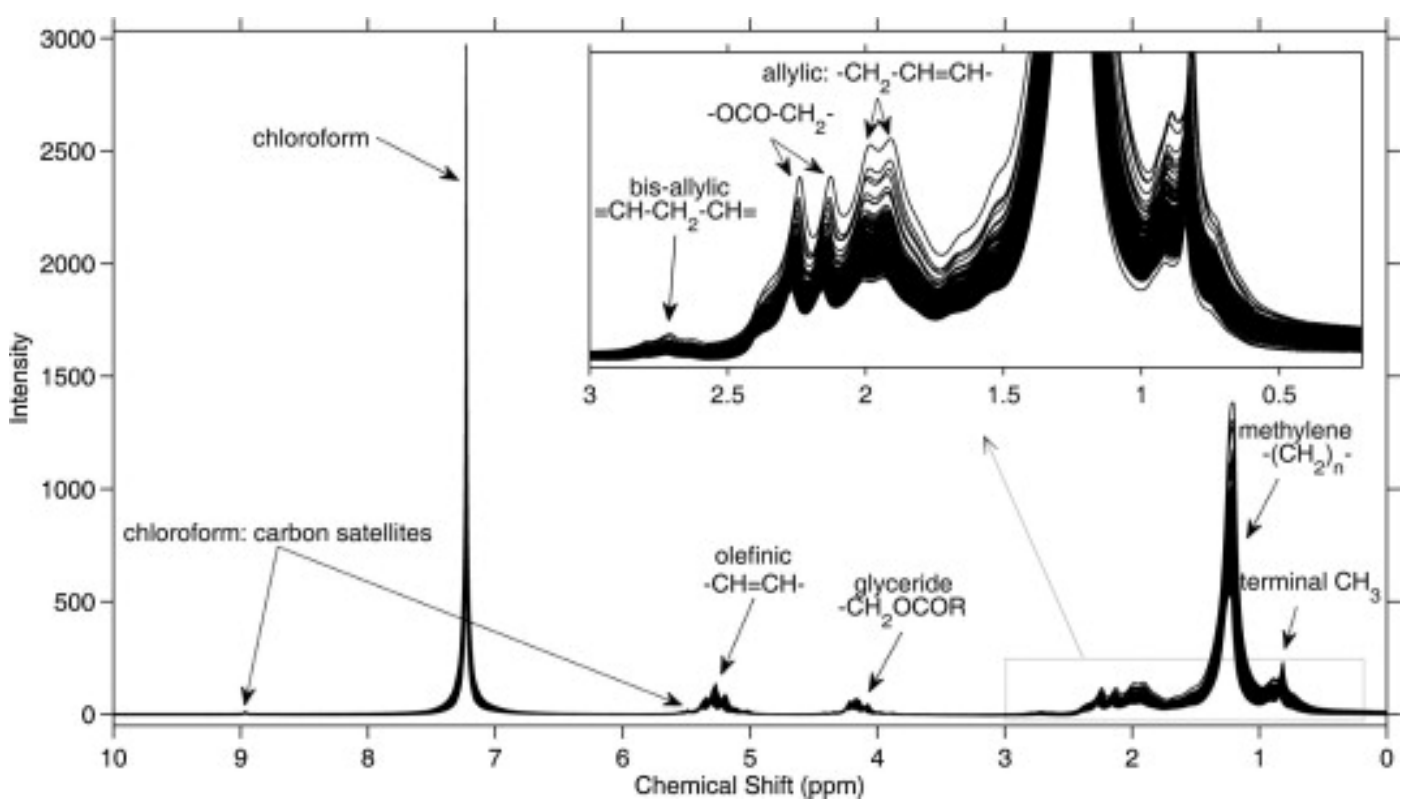

Figure 3. Extracted with permission from Ref [50]. Annotated $60 \mathrm{MHz}{ }^{1} \mathrm{H}$ NMR spectra for 20 extra virgin olive oils, 10 hazelnut oils and 144 olive oil-hazelnut oil mixtures. The inset shows an expansion of the $0.20-3.00 \mathrm{ppm}$ chemical-shift region.

In addition to the study of edible oils, fuel and biodiesel analysis has formed part of the work performed on compact NMR spectrometers in view of their relative portability and analysis costeffectiveness. Notably, there is a requirement for rapid and reliable quality control methods for diesel; 


\section{Analytica Chimica Acta 2019}

1 adulterants and contaminants substantially affect the properties of the fuel. A PLS regression model

2 has been developed through $\mathrm{LF}^{1} \mathrm{H}$ NMR experiments in order to determine a number of key

3 properties related to the fuel. Specifically, specific gravity, cetane number, flashpoint and distillation

4 temperatures could be compared through this PLS model, with errors less than or approaching those

5 of appropriate, more conventional analytical techniques. A univariate calibration curve was also

6 applied in order to derive the methyl and ethyl ester contents of biodiesel fuels from LF bNMR

7 experiments. It has been reported that compact NMR quality control and content experiments

8 generated comparable results to those of the current mid-IR reference technique; however, no prior

9 preparation of samples was necessary for the rapid scan times of $15 \mathrm{~s}$, an advantage which expands

10 the possibilities for this technique as part of a wider QC process [55].

11 LF NMR analysis has also been applied to fields such as plant biotechnology. Indeed, secondary

12 biomolecules present in hops, which include bitter acids, volatile monoterpenes and sesquiterpenes, are located in lupulin glands; extracellular trichomes are ideally suited to fast sample analyses with little prior preparation. Screening of the composition of these glands would allow for the selection of hops with particular aromatic properties, leading to the targeted breeding of particular strains. This direct method of LF NMR analysis has been found to not only generate reliable quality indicators for hops through combinations with chemometrics techniques, but this approach also avoided the complex extraction procedures usually employed for such analyses by other analytical techniques. This highlights the simplicity of compact benchtop techniques, and also circumvents the use of unsustainable and complex preparation practices [56].

Table 2. Benefits, limitations and potential future applications of LF bNMR analysis in food and agricultural chemistry. Limited references to relaxometry studies have been included for purposes of completion.

\begin{tabular}{|l|l|l|}
\hline Criterion & Comments & $\begin{array}{l}\text { Relevant } \\
\text { References }\end{array}$ \\
\hline $\begin{array}{l}\text { Applicability to } \\
\text { food standards and }\end{array}$ & $\begin{array}{l}\text { Both relaxation parameters and amplitudes are powerful } \\
\text { measures of the content and authenticity of intact foodstuffs. }\end{array}$ & {$[47]$} \\
\hline
\end{tabular}




\begin{tabular}{|c|c|c|}
\hline authenticity testing & $\begin{array}{l}\text { Standard protocols relying on fast, reliable measurements can } \\
\text { be developed and transferred into a quality control pipeline. }\end{array}$ & \\
\hline Sample preparation & $\begin{array}{l}\text { Little or no sample preparation is required. No sample } \\
\text { preparation at all is necessary for qualitative (identification) } \\
\text { purposes performed by LF spectrometers not requiring added } \\
{ }^{2} \mathrm{H}_{2} \mathrm{O} \text { or alternative deuterated NMR solvents. For the latter } \\
\text { class of facilities, in some cases only the direct transference of } \\
\text { samples to NMR tubes is required. Simple preparation is } \\
\text { essential, especially in the context of complex QC pipelines } \\
\text { and frameworks, where rapid, reliable measurements are } \\
\text { necessary. }\end{array}$ & {$[48,51]$} \\
\hline Selectivity & $\begin{array}{l}\text { For analyses of complex samples such as edible and frying oils, } \\
\text { with numerous resonances, it can be difficult to discern } \\
\text { particular features which would distinguish between variants of } \\
\text { the same types of sample (such as extra virgin olive oil vs. } \\
\text { hazelnut oil comparisons). The purity of the sample will affect } \\
\text { the level of selectivity, with pure samples of hazelnut oil and } \\
\text { olive oil being distinguishable by the integrals of unsaturated } \\
\text { fatty acid olefinic and olefinic-related resonances (of higher } \\
\text { intensities in }{ }^{1} \mathrm{H} \text { NMR spectra of hazelnut oils than in those of } \\
\text { olive oils). This applies equally to analyses of alternative } \\
\text { foodstuffs, with reasonable selectivity based on the complexity } \\
\text { of the analytes investigated. }\end{array}$ & {$[50,51]$} \\
\hline Sensitivity & $\begin{array}{l}\text { Capable of detection of adulteration of olive oil with hazelnut } \\
\text { oil at levels in excess of } 11 \%(\mathrm{w} / \mathrm{w}) \text {. Improved sensitivity for } \\
\text { the detection of oil adulteration at } 60 \mathrm{MHz} \text { when compared to } \\
\text { corresponding FTIR measurements. }\end{array}$ & {$[50]$} \\
\hline $\begin{array}{l}\text { Reproducibility of } \\
\text { Analytical Data }\end{array}$ & $\begin{array}{l}95 \% \text { confidence intervals for the analysis of edible oils are } \\
\pm 13 \%(\mathrm{w} / \mathrm{w}) \text {. }\end{array}$ & [50] \\
\hline $\begin{array}{l}\text { Reliability and } \\
\text { Performance }\end{array}$ & $\begin{array}{l}\text { Stability of measurements; repeat measurements across } \\
\text { multiple weeks yield little variance. Application of } \\
\text { chemometrics with supervised or unsupervised pattern } \\
\text { recognition approaches is inherently applicable for quality } \\
\text { control monitoring. } \\
\text { Most facilities employ traditional 5-mm diameter NMR tubes. } \\
\text { High sample throughput with rapid spectral acquisition. } \\
\text { Simple operation which can be automated within a continuous } \\
\text { flow set-up. }\end{array}$ & {$[47,48,50]$} \\
\hline Versatility & $\begin{array}{l}\text { Traditional LF NMR analysis is valuable for molecular } \\
\text { determinations, whilst single-sided portable NMR sensors are } \\
\text { more routinely used for whole foodstuff and packaged goods } \\
\text { analysis. }\end{array}$ & [47] \\
\hline Limitations & $\begin{array}{l}\text { Solid-state NMR with benchtop instruments is limited to } \\
\text { diffusion/relaxation studies through time-domain NMR. The } \\
\text { chemical shift is not readily resolved in these inhomogeneous } \\
\text { fields. However, it is possible to estimate indirect couplings, } \\
\text { affording a basic chemical analysis. The resolution of signals in } \\
\text { complex samples such as edible and cooking oils may be } \\
\text { limited, and hence leads to the implementation of rigorous } \\
\text { chemometrics techniques. }\end{array}$ & {$[13,48]$} \\
\hline
\end{tabular}




\section{Reaction monitoring and chemical transformations}

LF instruments have seen increased applications in process monitoring, in particular in

biotechnological engineering, where naturally heterogeneous disperse systems and their complex optical behaviour engender numerous analytical challenges. In-situ reaction monitoring using NMR flow cells has been available for high-field systems for many decades, often as part of a chromatographic or mass spectrometric set-up; however, this approach requires the employment of an expert in several different areas of analytical science (NMR, chromatography, mass spectrometry etc.), which is expensive and technically challenging. Benchtop NMR spectrometers therefore offer low-cost and user-friendly options to monitor reactions in both teaching [57] and research laboratory environments [58]. In 2015, Cronin and co-workers not only tracked reaction progress by monitoring starting materials and products using a benchtop NMR system, but also incorporated a feedback loop mechanism in order to modify the reaction composition, allowing reaction efficiency to be explored and optimised in real-time [31]. This concept has been developed in order to incorporate a laboratory plant design, such as in the synthesis of fluorinated compounds; the virtual $100 \%$ abundance, high frequency and receptivity properties and half spin nucleus of ${ }^{19} \mathrm{~F}$ render it suitable for NMR measurements in continuous flow systems, without the requirement for a solvent interference [59]. Additionally, Cortés-Borda and co-workers recently developed a modular, autonomous flow reactor, synthesising the natural product carpanone as a model system [60]. As a self-optimising procedural workflow, the equipment involved was designed to include either a high-performance liquid chromatographic analysis system or LF NMR spectrometer. The developmental system required no prior input regarding the reactions and systems involved in the experiment, leading to rapid optimisation of the synthetic route to the carpanone product.

Recent work in process development has reported several appropriate set-ups for calibration experiments, including connected $500 \mathrm{MHz}$ and $43 \mathrm{MHz}$ NMR facilities, together with Raman probes and UV/Vis spectrophotometers in order to test the viability of compact instruments as substitutes for 


\section{Analytica Chimica Acta 2019}

high-field NMR spectrometers employed for the investigation of complex processes. Most notably, data from variable temperature processes appear to show reasonable agreement between LF and HF NMR instruments, although high temperature calibrations can cause issues with the internallyregulated temperature of compact instruments [61]. Moreover, similar ideas can be applied to monitor reaction progress [62], such as neutralisation of the mustard gas simulant, 2-chloroethyl ethyl sulphide (CEES) [63]. This has been reported to take place using a portable continuous flow device, with fully selective sulphoxidation by $\mathrm{H}_{2} \mathrm{O}_{2}$ being monitored with a compact LF NMR instrument, which allows for real-time manipulation of reaction conditions. Alternatively, these compact NMR instruments have been applied in stopped-flow analysis methods within microreactors, a strategy permitting the optimisation of reaction times without the previously essential work-up procedures [64]. Additionally, the incorporation of a mesofluidic reactor within a continuous flow synthesis as a means of optimising acid-catalysed esterification, Knoevenagel condensation, Diels-Alder reactions, and alkylation processes allowed for reaction monitoring without the conventional requirement of bespoke flow cells. This was ascribable to the positioning of the LF NMR instrument after the back pressure regulator, which also permitted the effect of temperature on reaction completion to be monitored [65]. Such applications miniaturise previously-available, prohibitively large technologies, with the reported system being the size of a suitcase and possibly also appealing to the defence sector [66].

Compact, LF spectrometers have also been used to compare different methods of reaction monitoring, such as gas chromatography (GC) and high-field NMR analyses, as well as providing detection methods for other techniques, such as size-exclusion chromatography [67]. Importantly, such compact instruments can be applied directly within fume hoods, and have been used to monitor a variety of reactions and processes; critical reviews dedicated to these strategies are available $[68,69]$.

Recent work has employed a $1.0 \mathrm{~T}$ instrument in order to monitor the acid-catalysed acetalisation of para-nitrobenaldehyde with ethylene glycol. Peak integration was used to monitor the concentrations of the reacting species, and reaction conditions were varied to determine kinetic parameters. Extracted samples at set intervals were also analysed on a high-field 9.4 $\mathrm{T}$ instrument for comparative purposes, each method appearing to provide similar kinetic data. It has therefore been suggested that compact 
1 NMR instruments can also reliably be used for these types of kinetic studies as viable, more cost-

2 effective alternatives to those involving high-field spectrometers [70]. Fischer esterification, Suzuki

3 cross-coupling, and oxime formation have also served as proof-of-concept reactions for monitoring

4 with LF benchtop NMR analysis. These reactions were used as models for the consideration of such

5 instruments as process analytical technologies (PAT), which are complementary to other methods

6 such as IR and Raman spectroscopies. Reagents were required to be sufficiently concentrated for the

7 dynamic range with solvent compositions minimised, whilst achieving a 10:1 SNR at a $45 \mathrm{MHz}$

8 operating frequency [71]. All reactions were performed at the magnet temperature of $42^{\circ} \mathrm{C}$, limiting

9 the technology in this study to the ambient temperature range, whilst variable temperature alternatives

10 are now available [72].

Table 3. Benefits, limitations and potential future applications of LF benchtop NMR analysis in reaction monitoring and continuous flow systems.

\begin{tabular}{|c|c|c|}
\hline Criterion & Comments & $\begin{array}{l}\text { Relevant } \\
\text { References }\end{array}$ \\
\hline $\begin{array}{l}\text { Incorporation } \\
\text { within continuous } \\
\text { flow systems }\end{array}$ & $\begin{array}{l}\text { Although previously limited by the availability of variable } \\
\text { temperature probes, a number of parameters can now be } \\
\text { investigated by the incorporation of these instruments within a } \\
\text { continuous flow framework, and the spatial position of the } \\
\text { spectrometer within that protocol. In view of the variety of } \\
\text { manufacturers and sample requirements, the fine-tuning of } \\
\text { each system to a reaction monitoring process varies; however, } \\
\text { LF NMR experiments can successfully monitor the evolution } \\
\text { of both simple and complex chemical transformations. }\end{array}$ & {$[65,71,72]$} \\
\hline Sample preparation & $\begin{array}{l}\text { The requirement for deuterated solvents, for example, varies } \\
\text { between spectrometers and their manufacturing sources. } \\
\text { However, with the application of solvent suppression } \\
\text { techniques, or the incorporation of }{ }^{2} \mathrm{H}_{2} \mathrm{O} \text { as a field frequency } \\
\text { lock, this does not cause significant drawbacks in terms of } \\
\text { reaction monitoring; }{ }^{19} \mathrm{~F} \text { and other nuclei have been used as } \\
\text { probes in order to avoid interferences arising from the solvent. } \\
\text { Little or no sample preparation is required. No sample } \\
\text { preparation at all is necessary for qualitative (identification) } \\
\text { purposes performed by LF spectrometers not requiring added } \\
{ }^{2} \mathrm{H}_{2} \mathrm{O} \text {. For the latter class of facilities, in some cases only the } \\
\text { direct transference of samples to NMR tubes is required. }\end{array}$ & {$[59,72]$} \\
\hline Selectivity & $\begin{array}{l}\text { The monitoring of complex molecular structures within } \\
\text { continuous flow measurements becomes difficult with 1D } \\
\text { techniques in view of the lower chemical shift dispersion and } \\
\text { the likely involvement of second-order coupling patterns, } \\
\text { which give rise to an increased level of signal overlap. }\end{array}$ & {$[60,63,65,71]$} \\
\hline
\end{tabular}




\begin{tabular}{|c|c|c|}
\hline Sensitivity & $\begin{array}{l}\text { Concentrations of reaction materials must be sufficiently high } \\
\text { in order to minimise dynamic range problems with solvents. } \\
\text { However, SNRs of } 10: 1 \text {, which often represent the limit of } \\
\text { quantification, are achievable with LF NMR analysis. }\end{array}$ & {$[14,71]$} \\
\hline $\begin{array}{l}\text { Reproducibility of } \\
\text { analytical data }\end{array}$ & $\begin{array}{l}\text { A high level of precision is obtainable both within- and } \\
\text { between-assays. This is particularly relevant for the multiple } \\
\text { simultaneous measurements performed within a continuous } \\
\text { flow process. }\end{array}$ & [69] \\
\hline $\begin{array}{l}\text { Reliability and } \\
\text { performance }\end{array}$ & $\begin{array}{l}\text { Low cost, reliable determination of chemical structure and } \\
\text { dynamic effects through the incorporation of variable } \\
\text { temperature probes. } \\
\text { Most facilities employ traditional 5-mm diameter NMR tubes. } \\
\text { High sample throughput with rapid spectral acquisition. } \\
\text { Simple operation which can be automated within a continuous } \\
\text { flow set-up. }\end{array}$ & {$[31,65,71]$} \\
\hline Versatility & $\begin{array}{l}\text { Can be employed for reactants, intermediates and/or products } \\
\text { which are not readily responsive to or accessible by } \\
\text { alternative, non-NMR spectroscopic techniques such as } \\
\text { UV/Visible spectrophotometric and IR probing systems. For } \\
\text { example, those lacking chromophores and IR-active functions } \\
\text { respectively. }\end{array}$ & {$[68,71]$} \\
\hline Limitations & $\begin{array}{l}\text { LF NMR techniques, particularly when using } 1 \mathrm{D}{ }^{1} \mathrm{H} \\
\text { experiments, may struggle to monitor complex molecular } \\
\text { structures. Variable temperature processes necessitate specific } \\
\text { equipment, whilst reports of bubbles within the flow cell, as } \\
\text { well as precipitation, crystallisation, and the formation of } \\
\text { phases during the reaction will affect the viability of the } \\
\text { monitoring approach. Low SNRs are observed, with } 10: 1 \\
\text { remaining the recommended threshold. Automation is not yet } \\
\text { fully implemented in many instruments, although some } \\
\text { progress has been made in the development of bespoke } \\
\text { algorithms and chemical robotics, enhancing its potential use } \\
\text { as a robust PAT tool. }\end{array}$ & [71-73] \\
\hline
\end{tabular}

\section{Structural and forensic chemistry}

6 Chemical analysis techniques such as bNMR spectroscopy are routinely applied in the detection and assessment of illicit drugs or agents [74], whilst also being used as experimental procedures in the teaching of analytical chemistry [75,76]. A comprehensive assessment of the forensic applications of 
Analytica Chimica Acta 2019

1 LF compact, benchtop instruments recently described the structural characterisation and identification

2 of strychnine adulteration in chemical identification tests [66]. Using a combination of 1D and 2D

3 experiments, it was possible to identify strychnine and associated counter-ions through a

4 consideration of chemical shift values as signatures in $1 \mathrm{D}^{1} \mathrm{H}$ and ${ }^{13} \mathrm{C}$, and DEPT, as well as $2 \mathrm{D}$

5 COSY, HETCOR, HSQC and HMBC experiments at a magnetic field strength of only $1.0 \mathrm{~T}$. In this

6 extensive study, the molecular structure of strychnine was successfully identified through high-field

7 1D experiments, or alternatively via LF $1.0 \mathrm{~T}$ HMBC and HSQC approaches. This suggests that

8 compact bNMR analysis strategies can be effectively used as a tool for structural elucidation, but also

9 provides a viable and cost-effective solution to chemical forensic problems. Indeed, this $1.0 \mathrm{~T}$ facility

10 was found to provide valuable information regarding the identity of several strychnine salts,

11 employing their chemical shift signatures as structural descriptors based on the effects of heteroatoms

12 on adjacent protons, as well as the identification of adulterants therein (Figure 4) [66]. 


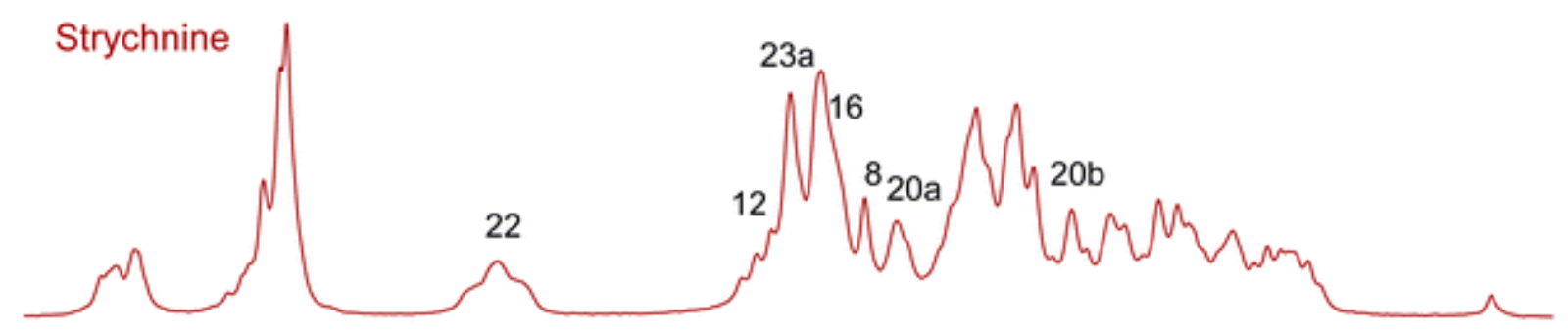

a)

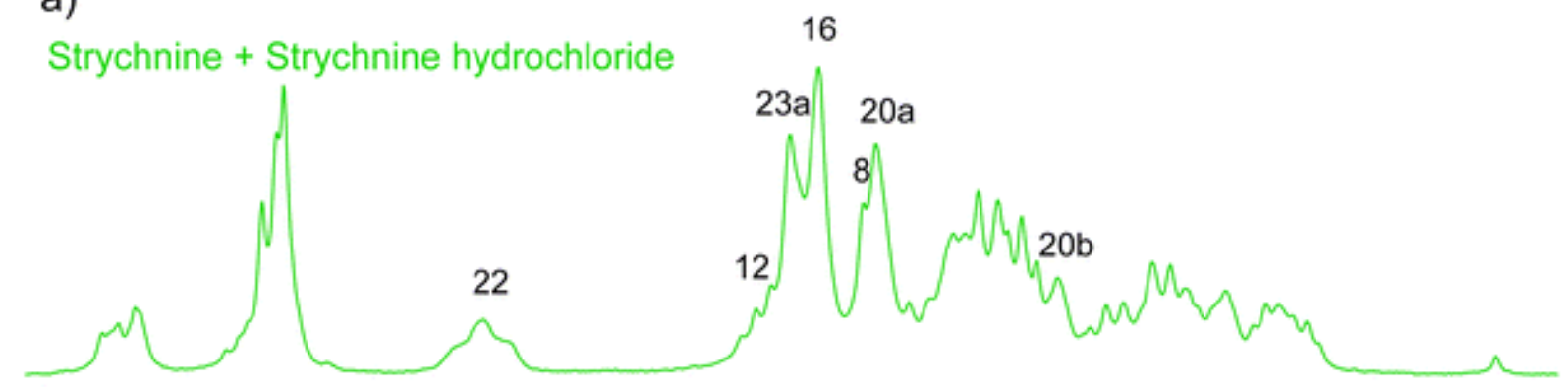

b)

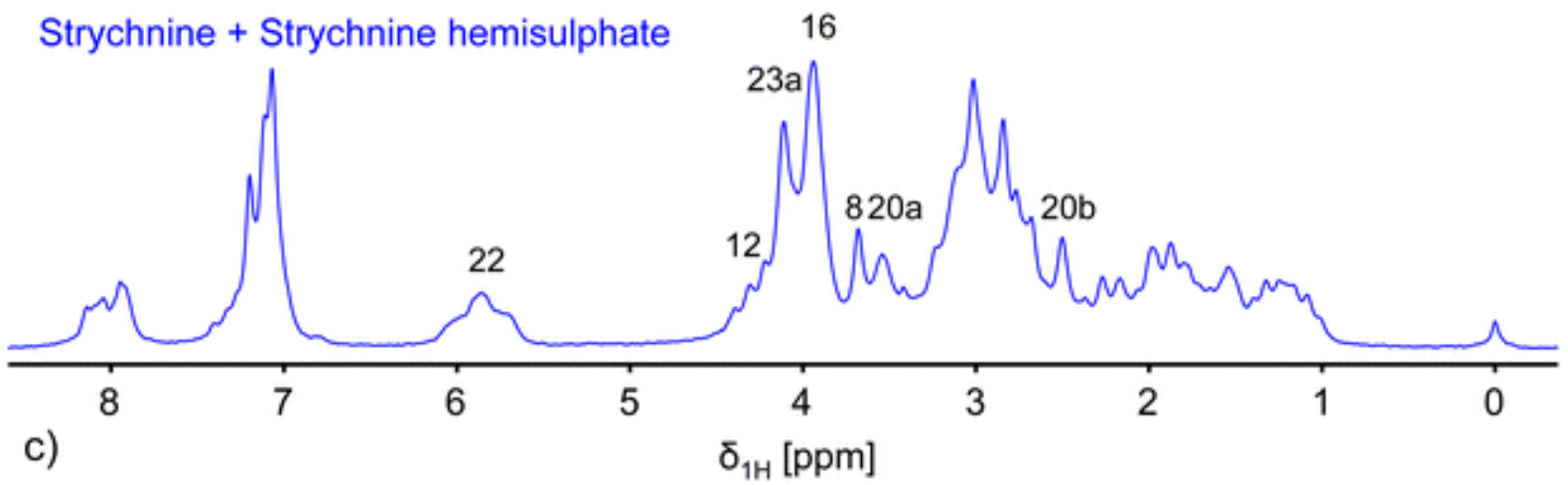

2 Figure 4. Reproduced from Ref [66] with permission from The Royal Society of Chemistry. 1D ${ }^{1} \mathrm{H}$

3 NMR spectra of strychnine and adulterated strychnine dissolved in $\mathrm{CDCl}_{3}$, and recorded at $1.0 \mathrm{~T}$. (a)

4 Strychnine $(135 \mathrm{mM}), 4$ scans. (b) Strychnine $(135 \mathrm{mM})$ and strychnine hydrochloride $(10 \mathrm{mM}), 4$

5 scans. (c) Strychnine and strychnine hemisulphate $(10 \mathrm{mM}), 4$ scans. Assignments are provided in the

6 ESI.

7 Benchtop NMR spectroscopy has been applied to the analysis of common illicit drugs such as

8 methamphetamine. Organic and P-containing precursor molecules were identified in samples obtained

9 from unregistered, so-called clandestine manufacturing laboratories. LF compact NMR analysis

10 successfully characterised ephedrine, pseudoephedrine, and methamphetamine, whilst also detecting

11 the P-containing precursors used during their synthetic routes [77].

12 Pharmaceutical and model systems were recently analysed using the first implementation of a DOSY pulse sequence on a LF NMR spectrometer. Indeed, Malet-Martino and co-workers [78] applied a 
bipolar pulse pair-stimulated echo sequence with a longitudinal eddy current delay pulse sequence on esomeprazole, paracetamol, and hypromellose, as well as other model systems, and obtained a LF DOSY map. Although implementation of the technique was robustly established on a LF NMR spectrometer, the authors recognised the issues associated with the sensitivity of this system, leading to longer acquisition times or the need for higher analyte concentrations in order to observe SNR values $>5$. This limits the range of application of this technique with current technology and methods, whilst the authors suggest this as a current approach for separating spectral profiles of different components in a mixture rather than obtaining accurate diffusion coefficients [78].

Therefore, in principal, the LF NMR analysis approach may soon be directly applied by forensic monitoring teams for the detection of illicit drugs and their synthetic precursors and by-products, together with traces of contaminating reaction solvents, 'on-site' at crime scenes, perhaps at policeraided clandestine laboratories or even roadsides. This will represent a major promising development in the forensic science area.

Table 4. Benefits, limitations and potential future applications of LF benchtop NMR analysis in chemical forensics and structural chemistry.

\begin{tabular}{|c|c|c|}
\hline Criterion & Comments & $\begin{array}{l}\text { Relevant } \\
\text { References }\end{array}$ \\
\hline $\begin{array}{l}\text { Mobile and field } \\
\text { applications }\end{array}$ & $\begin{array}{l}\text { Many forensic and point-of-interest assays will need to take place } \\
\text { outside traditional laboratory spaces; therefore, there is a } \\
\text { possibility of incorporating the technology of LF NMR } \\
\text { spectrometers into portable boxes or mobile laboratories. }\end{array}$ & {$[66]$} \\
\hline $\begin{array}{l}\text { Sample } \\
\text { preparation }\end{array}$ & $\begin{array}{l}\text { The requirement for deuterated solvents, for example, varies } \\
\text { between manufacturers; however, with the application of solvent } \\
\text { suppression techniques, or the incorporation of }{ }^{2} \mathrm{H}_{2} \mathrm{O} \text { as a field } \\
\text { frequency lock, this does not significantly limit the possibilities of } \\
\text { this technology in forensic and chemical identification testing. } \\
\text { Little or no sample preparation is required. No sample preparation } \\
\text { at all is necessary for qualitative (identification) purposes in } \\
\text { protocols performed by LF spectrometers not requiring added } \\
{ }^{2} \mathrm{H}_{2} \mathrm{O} \text {. For the latter class of facilities, in some cases only the } \\
\text { direct transference of samples to NMR tubes is required. }\end{array}$ & {$[77,79]$} \\
\hline Selectivity & $\begin{array}{l}\text { Particularly for the assignment of areas of strong overlap in }{ }^{1} \mathrm{H} \\
\text { spectral profiles, }{ }^{13} \mathrm{C} \text { experiments at } 1.0 \text { Tesla (chemical shift } \\
\text { range }>200 \mathrm{ppm} \text { ) can offer improved resolution of resonances. } \\
\text { These experiments suffer from low sensitivity and the effects of } \\
\text { the low abundance of }{ }^{13} \mathrm{C} \text { (only } 1.1 \% \text { ), yet at natural abundance, } \\
\text { there is an absence of homonuclear couplings between }{ }^{13} \mathrm{C} \text { nuclei. }\end{array}$ & {$[66,80]$} \\
\hline
\end{tabular}




\begin{tabular}{|c|c|c|}
\hline & $\begin{array}{l}\text { NOE signal enhancement, and }{ }^{1} \mathrm{H} \text { decoupling eliminates } \\
\text { heretonuclear multiplet splitting leading to full resolution of all } \\
22{ }^{13} \mathrm{C} \text { resonances in the NMR spectrum of strychnine in } 4,096 \\
\text { scans (the total acquisition taking } 5.68 \text { hours). }\end{array}$ & \\
\hline Sensitivity & $\begin{array}{l}\text { 1D }{ }^{1} \mathrm{H} \text { experiments offer much valuable qualitative, structural } \\
\text { determination potential. However, 2D techniques provide } \\
\text { additional information, in addition to improvements in sensitivity, } \\
\text { in particular for structural elucidation purposes. HSQC } \\
\text { experiments represent fast, spectroscopically-indirect } \\
\text { measurements for }{ }^{1} \mathrm{H} \text { nuclei. } 2 \mathrm{D} \text { HSQC NMR analysis of } \\
\text { strychnine present at a level of } 135 \mathrm{mmol} \text { per NMR tube was } \\
\text { acquired in } 128 \text { scans for each time-step, and a total experimental } \\
\text { time of } 22.7 \text { hours (repetition time } 10 \mathrm{~s} \text { ). A HETCOR spectrum of } \\
\text { the same molecule acquired within the same time period } \\
\text { exhibited lower intensity, and afforded lower SNR values than } \\
\text { those of equivalent HSQC experiments. }\end{array}$ & {$[14,66]$} \\
\hline $\begin{array}{l}\text { Reproducibility } \\
\text { of Analytical } \\
\text { Data }\end{array}$ & $\begin{array}{l}\text { A high level of precision is obtainable both within- and between- } \\
\text { assays. Considering the high reproducibility/low repeat between- } \\
\text { assay component -of-variance established in this study for } \\
\text { biofluid measurements (Table 5), reproducibility should be high } \\
\text { for structural determination experiments. }\end{array}$ & {$[80]$} \\
\hline $\begin{array}{l}\text { Reliability and } \\
\text { Performance }\end{array}$ & $\begin{array}{l}\text { Low cost, reliable determination of chemical structure and } \\
\text { authenticity through 1D and 2D experiments. } \\
\text { Adequate resolution, stability and sensitivity for both } 1 \mathrm{D} \text { and } 2 \mathrm{D} \\
\text { experiments in order to permit the reliable determination of } \\
\text { complex structures such as those of drugs and biomolecules. }{ }^{1} \mathrm{H} \\
\text { resonances are reliably assigned through } 2 \mathrm{D} \text { HETCOR, HSQC } \\
\text { and COSY experiments, whilst a } 2 \mathrm{D} J \text {-resolved methodology will } \\
\text { facilitate the identification of fine structure. }{ }^{1} \mathrm{H} \text { and }{ }^{13} \mathrm{C} \\
\text { experiments are available, allowing for significant multivariate } \\
\text { data to be obtained and correlated for robust structural } \\
\text { determinations. } \\
\text { Most facilities employ traditional 5-mm diameter NMR tubes. } \\
\text { High sample throughput with rapid spectral acquisition. } \\
\text { No major requirement for specialist NMR/technical staff for } \\
\text { operation, i.e. there is no need for operating staff to understand } \\
\text { and interpret spectral profile data, and this renders LF NMR } \\
\text { facilities suitable for use by investigative crime scene field or } \\
\text { forensic workers directly at their crime scene sites, i.e. no } \\
\text { laboratory is required. } \\
\text { Experimental time is longer than that of high-field techniques; } \\
\text { however, the relative ease of use, absence of cryogenic facilities } \\
\text { and compact nature render this technique is particularly suited to } \\
\text { forensic and chemical forensic applications in the field. }\end{array}$ & [81] \\
\hline Versatility & $\begin{array}{l}\text { The study of small, complex molecules with LF NMR } \\
\text { spectroscopy, as well as the electrostatic interactions of dissolved } \\
\text { ions, suggests a viable role in forensic analysis and mobile } \\
\text { chemical assay systems. }\end{array}$ & [74] \\
\hline
\end{tabular}




\begin{tabular}{|l|l|l|}
\hline Limitations & $\begin{array}{l}\text { Long experimental times for robust structural analyses and 2D } \\
\text { experiments, whilst 1D techniques suffer from some selectivity } \\
\text { issues. }\end{array}$ & {$[66]$} \\
\hline
\end{tabular}

\section{Potential biofluid screening and metabolomics applications of LF benchtop NMR analysis}

High- and very high-field NMR spectroscopic techniques continue to serve as extremely useful, and now extremely-sensitive probing tools for the simultaneous multicomponent analysis of complex biofluids collected from humans and other living systems. A very high level of valuable information regarding the molecular nature and concentrations of a plenitude of endogenous biomolecules, along with exogenous agents present in such fluids (e.g., human urine, blood plasma, knee-joint synovial fluid, cerebrospinal fluid and salivary supernatants), can be acquired from such investigations. These approaches offer much potential regarding the investigation of metabolic processes, and when linked with multidimensional data analysis techniques in metabolomics strategies, serve as extremely powerful means of probing, for example, the biomolecular basis of many human diseases. For example, statistically significant differences between the concentrations of one or more biofluid metabolites, or patterns of such metabolites, in human disease versus healthy control biofluid profile comparisons, conceivably arise from disturbances or perturbations to key metabolic pathways featured in disease aetiologies, developments and/or progressions. Such studies may also yield much valuable diagnostic and/or prognostic screening information, including that involving the seeking, identification and validation of dependable and potentially predictive biomarkers. NMR-based metabolomics strategies may also be applied to the multicomponent analysis of many biomolecules in tissue biopsies and cultured cells (either directly via the analysis of intact samples using ${ }^{1} \mathrm{H}$ highresolution magic angle spinning (MAS)-NMR analysis technologies, or indirectly as pre-selected solution extract matrices).

Recently, Percival et. al.[12] demonstrated the very first application of LF benchtop NMR technologies to the ${ }^{1} \mathrm{H}$ NMR-based metabolomics analysis of human urine, in this case for the diagnosis and monitoring of type 2 diabetes patients. This study fully established that such an analytical strategy was successful in detecting and quantifying key urinary biomarkers for this 


\section{Analytica Chimica Acta 2019}

1 condition, despite a series of resonance overlap problems arising from the low operating frequency

2 involved (resonances with similar linewidths appear increasingly broader at decreasing field strengths within the overall $c a .10 \mathrm{ppm}$ spectral width in ppm). Moreover, it also provided a bioanalytical 'blueprint' protocol for the future performance of such LF metabolomics explorations.

In addition to expected upregulations in urinary glucose, and ketone bodies such as 3-Dhydroxybutyrate, this investigation found that acetate, alanine, citrate, and creatine/creatinine also had significantly higher concentrations in type 2 diabetic urine samples than those of healthy control participants, together with downregulations in aromatic biomolecules, particularly hippurate and indoxyl sulphate (which presumably arise from diabetic polyuria). These results were in accordance with those obtained in a corresponding high-field $(600 \mathrm{MHz}){ }^{1} \mathrm{H}$ NMR study performed on human urine [82]. Multivariate metabolomics analysis of these $60 \mathrm{MHz}{ }^{1} \mathrm{H}$ NMR profiles by PCA, partialleast squares and orthogonal partial-least squares discriminatory analysis (PLS-DA and OPLS-DA respectively), support vector machine (SVM)-based receiver operating characteristic (ROC) curve analysis, and random forest (RF) models demonstrated a very high level of distinction between these two sample classifications. There was very good agreement between estimations of urinary glucose concentrations obtained at both 60 and $400 \mathrm{MHz}$ operating frequencies, and those determined by both approaches correlated very significantly with those estimated by a non-NMR spectrophotometric method based on a glucose oxidase system.

Typical LF $60 \mathrm{MHz}{ }^{1} \mathrm{H}$ NMR profiles acquired on urine specimens collected from type 2 diabetic and healthy control participants are shown in Figures 5(a) and (b) respectively for comparative purposes. The clear spectral differences observed between these profiles (particularly the observation of glucose signals in the type 2 diabetic sample and their absence from the healthy control samples) are, at least in principle, interpretable by non-specialist healthcare staff. It is also anticipated that the portable benchtop NMR system employed in the laboratory for the diagnosis and prognostic monitoring of diabetes by clinical and bioanalytical chemists, may be routinely managed and operated by such untrained, non-NMR specialist staff when implemented in hospital or alternative point-of-care health settings such as smaller general practice health centres, dental surgeries and community pharmacies. 


\section{Analytica Chimica Acta 2019}

1 For one of the more prominent resonances visible in the benchtop $60 \mathrm{MHz}{ }^{1} \mathrm{H}$ NMR profiles acquired on type 2 diabetic urine samples, i.e. that attributable to the $-\underline{\mathrm{C}}_{3}$ function of lactate $(d, \delta=1.33 \mathrm{ppm})$, the $J$ value of this resonance is $7.00 \mathrm{~Hz}$ [83], and therefore it will envelop $2 \times 7.00 / 60=0.233 \mathrm{ppm}$ at this operating frequency, but only $2 \times 7.00 / 400=0.035 \mathrm{ppm}$ at $400 \mathrm{MHz}$. Hence, at least some caution is required regarding determinations of biomolecular analytes in biofluids via LF benchtop NMR analysis, especially on consideration of inherent signal overlap complications. Notwithstanding, these interferences are considered minimal for the determination of major urinary metabolites, i.e. those with prominent resonances in spectra acquired which have only a limited level of overlap with lower intensity signals, e.g. those of the citrate- $\underline{\mathrm{C}}_{2}$ - and acetate- $\underline{\mathrm{CH}}_{3}$ functions at $\delta=2.65$ (AB coupling pattern) and $1.92 \mathrm{ppm}(s)$ respectively, which include endogenous metabolites, chemopathological diagnostic biomarkers, and xenobiotics present at high or very high concentrations when expressed as a proportionate function of the total ${ }^{1} \mathrm{H}$ NMR spectral intensity, i.e. as in constant sum normalisation (CSN) methodologies. For example, the mean \pm SEM urinary level of 3-Dhydroxybutyrate in the type 2 diabetic urine samples investigated was $3.12 \pm 0.99 \mathrm{mmol} / \mathrm{L}$ (upregulated 13-fold over that of healthy controls), and therefore it is readily monitored in LF $60 \mathrm{MHz} \mathrm{NMR}$ spectra, provided that it is within the limit of quantification (LOQ) value estimated in samples to be tested. Moreover, ${ }^{1} \mathrm{H}$ NMR-active molecules with resonances located within interferant-free regions of the profiles obtained such as formate $(\delta=8.46 \mathrm{ppm})$ are also readily quantifiable. If focused on biomolecule resonances with clearly-visible singlet, doublet or triplet resonances, the analytical sensitivity of the LF benchtop spectrometer employed was excellent. Indeed, further experiments established that the limit of quantification (LOQ) for the additional ketone body acetone (arising from the decomposition of acetoacetate in vivo) was only $25 \mu \mathrm{mol} / \mathrm{L}$ at an operating frequency of $60 \mathrm{MHz}$ [12].

Analytical ${ }^{1} \mathrm{H}$ NMR response problems encountered with the 'intensity dampening' of glucose's $\alpha$ anomer $\mathrm{C} 1-\underline{\mathrm{H}}$ resonance employed for quantification purposes $(\delta=5.25 \mathrm{ppm})$ by the $\mathrm{H}_{2} \mathrm{O} / \mathrm{HOD}$ presaturation process employed in $\mathrm{LF}^{1} \mathrm{H}$ NMR determinations of total urinary glucose concentrations (optimised at $\delta=4.95 \mathrm{ppm}$ ), were overcome by the rigorous employment of prepared calibration 


\section{Analytica Chimica Acta 2019}

1 standards for all spectrometers utilised, both at 60 and $400 \mathrm{MHz}$ operating frequencies. A further

2 limitation found was attributable to significant differences between intra-molecular relaxation times

3 for selected biomolecules with two or more magnetically-distinguishable ${ }^{1} \mathrm{H}$ nuclei, together with any

4 long-range coupling effects.

5 Prominent protein-based and low-molecular-mass metabolite resonances were also observable in

6 single-pulse ${ }^{1} \mathrm{H}$ NMR spectra of human blood plasma acquired on a $60 \mathrm{MHz}$ LF benchtop facility, the

7 most intense being those assignable to lipoprotein-associated triacylglycerol fatty acid chains, and

8 'acute-phase' glycoprotein carbohydrate side-chain $\mathrm{N}$-acetylglucosamine and $\mathrm{N}$-acetylneuraminate

9 residues (predominantly those of $\alpha_{1}$-acid glycoprotein for the latter), along with those of glucose's

10 carbohydrate ring protons.

11 Overall, the authors recommended that in all future LF benchtop NMR-linked metabolomics

12 investigations, researchers should primarily focus on the most highly prominent signals which are

13 singlets, or those which have simple first-order coupling patterns (i.e. doublets, triplets, etc.) visible in

14 spectra acquired for quantification purposes. However, notable exceptions to this guideline include

15 targeted biomolecular analytes present at high or very high biofluid concentrations, for example

16 glucose and ketone bodies found in urine specimens collected from uncontrolled or poorly-controlled

17 diabetic patients. The technique is also likely to be applicable to the diagnosis of further metabolic

18 diseases, and further investigations to explore this are currently in progress. 
(a)

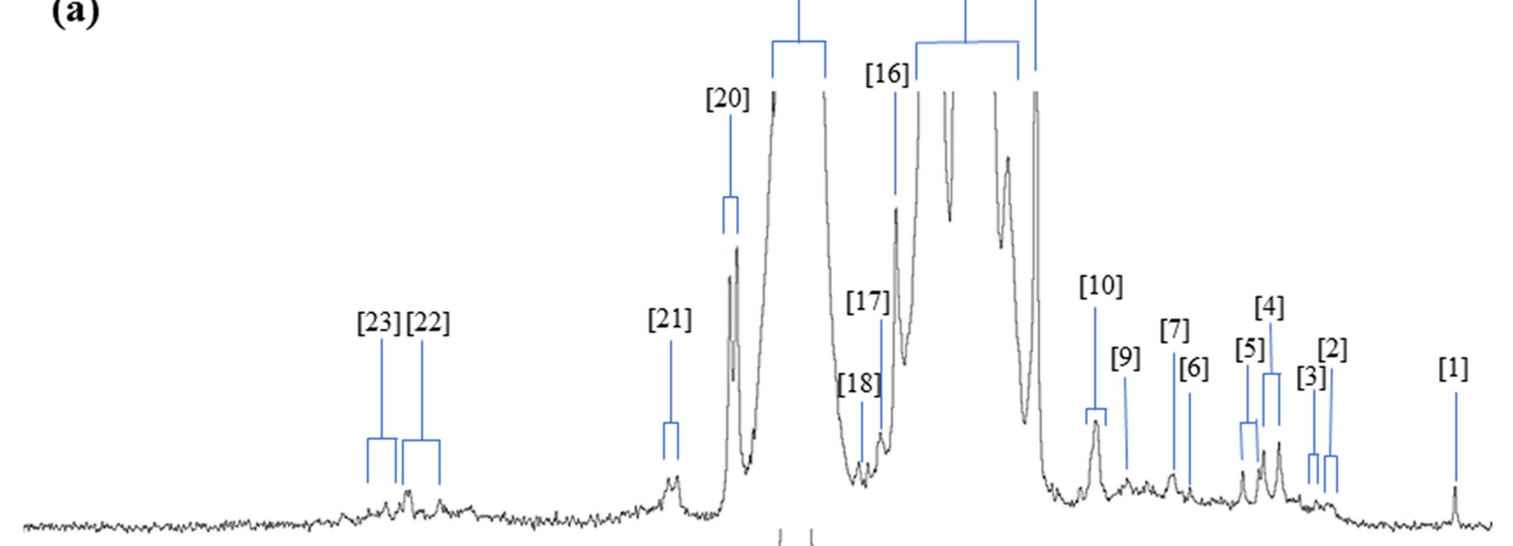

(b)

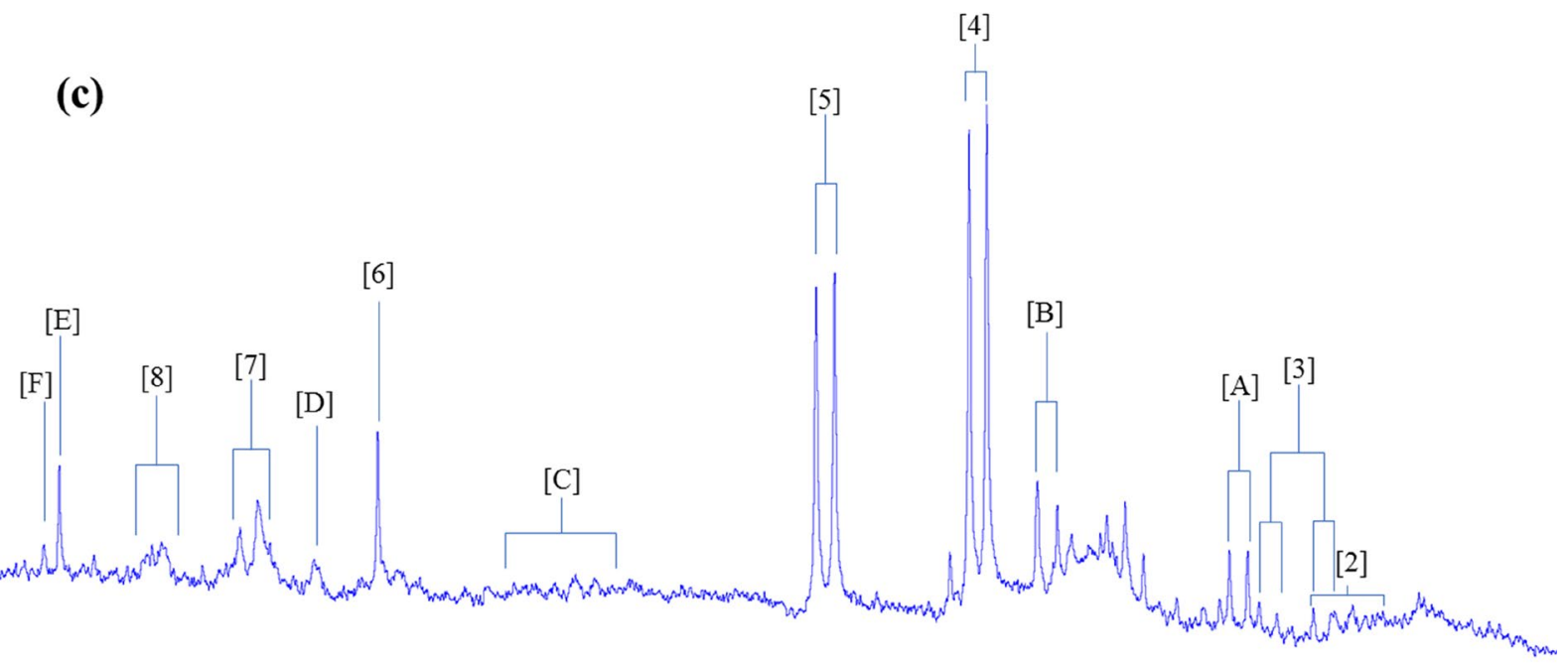


Figure 5. (a) and (b), LF $60 \mathrm{MHz}{ }^{1} \mathrm{H}$ bNMR profiles of human urine samples collected from type 2 diabetic and healthy control participants respectively. (c), Expanded 0.60-2.30 ppm region of the corresponding $400 \mathrm{MHz}$ spectrum of that shown in (a). Typical spectra are shown. Abbreviations: [1], 3-trimethylsilyl-(2,2,3,3-2 $\left.{ }^{2} \mathrm{H}_{4}\right)$-1-propionate-Si $\left(\mathrm{CH}_{3}\right)_{3}$ [TSP, internal chemical shift reference and quantitative ${ }^{1} \mathrm{H}$ NMR internal standard $\left.(\delta=0.00 \mathrm{ppm})\right]$; [2], isoleucine/leucine/valine- $\mathrm{CH}_{3} ;$ [3], valine- $\underline{\mathrm{C}}_{3} ;$ [4], lactate- $\underline{\mathrm{H}}_{3} ;[5]$, alanine- $\underline{\mathrm{H}}_{3} ;[6]$, acetate- $\mathrm{C}_{3} ;$ [7], glutamate- $\beta-\mathrm{C}_{2} / \mathrm{N}$-acetyl amino acids and N-acetylsugar-NHCOC$\underline{H}_{3} ;[8]$, glutamine- $\beta-\mathrm{C}_{2} ;[9]$, glutamine- $\gamma-\underline{\mathrm{C}}_{2} ;[10]$, citrate- $\underline{\mathrm{C}}_{2}-$

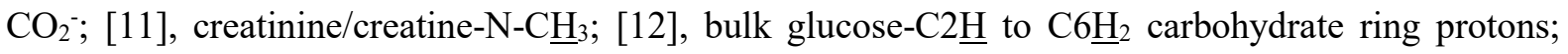
[13], trimethylamine-N-oxide- $\mathrm{N}\left(\mathrm{C}_{3}\right)_{3} ;$ [14], glycine- $\underline{\mathrm{C}}_{2} ;$ [15], creatine- $\underline{\mathrm{H}}_{2} ;$ [16], creatinine- $\mathrm{C}_{2}$; [17], [18], unassigned; [19], residual $\mathrm{H}_{2} \mathrm{O} / \mathrm{HOD}$; [20], $\alpha$-glucose-C1- $\underline{\mathrm{H}}$; [21], urea-CO-N$\underline{\mathrm{H}}_{2}$; [22], indoxyl sulphate aromatic ring protons; [23], hippurate aromatic ring protons. [A] to [F] correspond to resonances which were detectable at an operating frequency of $400 \mathrm{MHz}$ in this particular type 2 diabetic urine sample, but not so at $60 \mathrm{MHz}$ : [A], iso-butyrate- $\underline{\mathrm{C}}_{3}$ groups; [B], 3-D-hydroxybutyrate$\mathrm{CH}_{3} ;[\mathrm{C}]$, lysine- $\delta-\mathrm{C}_{2} ;[\mathrm{D}]$, proline- $\gamma$ - and $\delta-\mathrm{CH}_{2}$ groups; [E], acetone- $\underline{\mathrm{C}}_{3} ;[\mathrm{F}]$, acetoacetate- $\mathrm{C}_{3}$.

Table 5. Benefits, limitations and potential future applications of the LF benchtop NMR analysis of human or animal biofluids, and liquid biopsies.

\begin{tabular}{|c|c|c|}
\hline Criterion & Comments & $\begin{array}{l}\text { Relevant } \\
\text { References }\end{array}$ \\
\hline $\begin{array}{l}\text { Requirement for } \\
\text { deuterated NMR } \\
\text { solvents } \\
\text { (particularly }{ }^{2} \mathrm{H}_{2} \mathrm{O} \text { ) }\end{array}$ & $\begin{array}{l}\text { Many LF-NMR analysis systems do require deuterated NMR } \\
\text { solvents [some exclusively so, and some only as a field } \\
\text { frequency lock, } c a \text {. } 10 \%(\mathrm{v} / \mathrm{v}){ }^{2} \mathrm{H}_{2} \mathrm{O} \text { ], but selected spectrometers } \\
\text { operate effectively without such a requirement. }\end{array}$ & {$[12,84]$} \\
\hline $\begin{array}{l}\text { Sample } \\
\text { preparation }\end{array}$ & $\begin{array}{l}\text { Little or none required. No sample preparation at all is necessary } \\
\text { for qualitative (identification) purposes performed by LF } \\
\text { spectrometers not requiring added }{ }^{2} \mathrm{H}_{2} \mathrm{O} \text {. For the latter class of } \\
\text { facilities, in some cases only the direct transference of samples } \\
\text { to NMR tubes is required. }\end{array}$ & {$[12,84]$} \\
\hline Selectivity & $\begin{array}{l}\text { Limited, but the most prominent resonances (i.e. those of } \\
\text { relatively high concentration biomolecules), which are clearly } \\
\text { visible and predominantly unaffected by minor potentially } \\
\text { interfering signals, may be spectroscopically monitored. Those } \\
\text { located in spectroscopically-clear regions are also accessible to } \\
\text { quantification. } \\
\text { Application of 2D COSY and TOCSY options available } \\
\text { facilitates the rapid confirmation of identity assignments. } \\
\text { However, these developments will markedly improve with the } \\
\text { future availability of LF benchtop NMR spectrometers of higher } \\
\text { operating frequencies. }\end{array}$ & {$[12,84]$} \\
\hline Sensitivity & $\begin{array}{l}\text { Surprisingly and disproportionately high: LLOD values of }<50 \\
\mu \text { mol./L for selected metabolites with prominent }-\mathrm{CH}_{3} \text { and/or }- \\
\mathrm{CH}_{2} \text { - function singlet resonances present in aqueous model } \\
\text { solutions. SNR values }>10 \text { achievable at concentrations of } \geq 25 \\
\mu \text { mol./L for acetone. }\end{array}$ & {$[12,84]$} \\
\hline $\begin{array}{l}\text { Metabolite } \\
\text { quantification }\end{array}$ & $\begin{array}{l}\text { Particularly suited to the determination of acetate, alanine, } \\
\text { branched-chain amino acids (BCAAs), lactate, N-acetyl storage }\end{array}$ & {$[12]$} \\
\hline
\end{tabular}




\begin{tabular}{|c|c|c|}
\hline potential & $\begin{array}{l}\text { compounds, citrate, creatinine/creatine, formate, } 3 \text {-D- } \\
\text { hydroxybutyrate, urea, indoxyl sulphate, hippurate, } 3 \text {-D- } \\
\text { hydroxybutyrate, acetone and total glucose in human urine. } \\
\text { Excellent agreements were found between LF } 60 \mathrm{MHz} \text { benchtop } \\
\text { spectrometer determinations of glucose and those performed at } \\
\text { high-field ( } 400 \mathrm{MHz} \text { ). There was also a very highly significant } \\
\text { correlation between these } 60 \mathrm{MHz} \text { values and those generated by } \\
\text { a non-NMR method. } \\
\text { Very reliable linear internal standard-normalised intensity vs. } \\
\text { analyte concentration calibration standard plots readily facilitate } \\
\text { the determination of a range of biofluid metabolite } \\
\text { concentrations. } \\
\text { Problems are encountered with the determination of metabolites } \\
\text { involving the electronic integration of resonances located in } \\
\text { close proximity to the } \mathrm{H}_{2} \mathrm{O} / \mathrm{HOD} \text { presaturation frequency. } \\
\text { However, such problems may be overcome via the integration of } \\
\text { alternative signals of biomolecules of interest (if available and } \\
\text { accessible), and/or the employment of suitable pre-validated } \\
\text { calibration standards for the particular LF NMR spectrometer } \\
\text { employed. Careful pre-selection and optimisation of the } \\
\text { presaturation frequency and its power setting aids such analyses. } \\
\text { At least some of these metabolites, together with propionate, and } \\
\text { further ones of relatively high concentration and with }{ }^{1} \mathrm{H} \text { NMR } \\
\text { resonances with simple (first-order) coupling patterns such as } \\
\text { glycine, methanol and succinate, are also quantifiable in human } \\
\text { saliva (data not shown). }\end{array}$ & \\
\hline $\begin{array}{l}\text { Reproducibility of } \\
\text { analytical data }\end{array}$ & $\begin{array}{l}\text { A high level of precision is obtainable both within- and between- } \\
\text { assays. Typical 'within-assay' mean } \pm \text { SD values obtained for } \mathrm{n}= \\
11 \text { repeat citrate determinations made on a single } 20.00 \mathrm{mmol} / \mathrm{L} \\
\text { calibration standard sample was } 19.86 \pm 0.15 \mathrm{mmol} / \mathrm{L} \\
\text { (coefficient of variation only } 0.75 \% \text { ). } \\
\text { Typical 'between-assay' coefficients of variation for urinary } \\
\text { citrate (AB coupling pattern, } \delta=2.65 \mathrm{ppm} \text { ), trimethylamine-N- } \\
\text { oxide }(s, \delta=3.23 \mathrm{ppm} \text { ), glycine }(s, \delta=3.60 \mathrm{ppm}) \text {, creatinine (- } \\
\mathrm{CH}_{2} \text { - function } s, \delta=4.04 \mathrm{ppm} \text { ) and indoxyl sulphate ( } 2 \text { x sets of } \\
\text { aromatic proton } d d \mathrm{~s}, \delta=7.24 \mathrm{ppm}) \text { concentration } \\
\text { determinations were } 5.6,4.1,7.3,4.7-5.6 \text { and } 2.9 \% \text { respectively } \\
(\mathrm{n}=2 \text { or } 3 \text { repeat measurements performed). }\end{array}$ & [12] \\
\hline $\begin{array}{l}\text { Reliability and } \\
\text { performance }\end{array}$ & $\begin{array}{l}\text { Offers a very convenient, high-performance biomedical/clinical } \\
\text { chemistry NMR analysis system at a cost which is much lower } \\
\text { than that which involves more traditional HF NMR } \\
\text { spectrometers. } \\
\text { Provides a rapid and reliable strategy for the multicomponent } \\
\text { analysis of human biofluids or liquid aspirates/biopsies at their } \\
\text { site of collection (e.g. at health centres, dental surgeries and/or } \\
\text { pharmacies), or even outdoors in the field (e.g. at crime scene } \\
\text { investigations). These facilities are quickly installed at such sites } \\
\text { - the installation of HF NMR facilities with superconducting } \\
\text { magnets is simply not feasible under these circumstances for }\end{array}$ & {$[12,84]$} \\
\hline
\end{tabular}




\begin{tabular}{|c|c|c|}
\hline & $\begin{array}{l}\text { logistical reasons. It has a small space 'footprint', and the } \\
\text { methods developed involve little or no sample preparation. } \\
\text { Most facilities employ traditional 5-mm diameter NMR tubes. } \\
\text { High sample throughput (up to ca. } 60 \text { samples per } 24 \text { hr. period), } \\
\text { with rapid spectral acquisition. } \\
\text { No major requirement for specialist NMR/technical staff for } \\
\text { management and operation, i.e. there is no requirement for such } \\
\text { personnel to acquire spectra, nor for such operating staff to } \\
\text { understand and interpret spectral profile data, and this renders } \\
\text { LF NMR facilities suitable for use on-site by clinical nursing } \\
\text { staff, or investigative field or forensic workers at their points of } \\
\text { contact. } \\
\text { Highly suited to the pre-screening of samples prior to their } \\
\text { analysis at higher operating frequencies, i.e. at } \geq 500 \mathrm{MHz} \text {. For } \\
\text { example, LF NMR instruments may be employed to simply } \\
\text { detect glucose and/or ketone bodies in the urine of suspected } \\
\text { diabetic or pre-diabetic patients so that a full urinary }{ }^{1} \mathrm{H} \text { NMR } \\
\text { screen can then be performed at HF. }\end{array}$ & \\
\hline Versatility & $\begin{array}{l}\text { Applicable to most, if not all, biofluids and liquid tissue biopsy } \\
\text { extracts, but particularly valuable for those containing little or no } \\
\text { protein and other macromolecules, e.g. human urine and salivary } \\
\text { supernatants. Both single-pulse and Carr-Purcell-Meiboom-Gill } \\
\text { (CPMG) pulse sequence-filtered spectra may be acquired on } \\
\text { human blood plasma samples, and others with relatively high } \\
\text { protein contents. }\end{array}$ & {$[12,85]$} \\
\hline Limitations & $\begin{array}{l}\text { With the exception of biomolecules present at very high biofluid } \\
\text { concentrations (such as } \alpha \text { - and } \beta \text {-glucose anomers in } \\
\text { uncontrolled or poorly-controlled diabetic urine specimens), } \\
\text { currently not readily suitable for the determination of } \\
\text { metabolites containing }{ }^{1} \mathrm{H} \text { nuclei with complex coupling patterns } \\
\text { (which give rise to higher-order multiplets), nor to those with } \\
\text { low intensity signals which are at least partially obscured by } \\
\text { more prominent ones such as lactate- and acetate- } \mathrm{CH}_{3} \text { function } \\
\text { resonances. However, this problem may also be experienced in } \\
\text { high-field NMR analysis, especially at operating frequencies } \leq \\
500 \mathrm{MHz} \text {. } \\
\text { 'Intensity-dampening' problems experienced with the integration } \\
\text { of resonances with chemical shift values similar to that of the } \\
\mathrm{H}_{2} \mathrm{O} / \mathrm{HOD} \text { presaturation frequency are readily rectifiable (please } \\
\text { refer to metabolite quantification potential column above). } \\
\text { Similar, albeit less marked, complications were also encountered } \\
\text { at an operating frequency of } 400 \mathrm{MHz} \text {. } \\
\text { An additional complication arises from significant differences } \\
\text { between intra-molecular relaxation times for analytes with two } \\
\text { or more magnetically-distinct }{ }^{1} \mathrm{H} \text { nuclei; however, limitation of } \\
\text { intensity integrations for quantification purposes to the most } \\
\text { intense resonances with simple first-order coupling patterns is } \\
\text { recommended in such cases. }\end{array}$ & {$[12,84]$} \\
\hline
\end{tabular}


\begin{tabular}{|l|l|l|}
\hline & \\
\hline
\end{tabular}

1

\section{Conclusions}

The developing field of compact benchtop NMR instruments for chemical and biochemical analysis has recently rapidly expanded, both in terms of applications and advanced methodologies.

Applications now range from biomedicine, through to advanced energy research and materials science, highlighting the versatility of the technique, together with the great strides that early innovators and current specialists are making in transitioning this technique into an over-arching, viable LF alternative to the expensive, larger instruments available in an increasing number of research areas and industry. Indeed, most recently, Cronin and co-workers have pioneered a novel machine-learning framework for probing chemical reactivity, in an 'organic synthesis robot', incorporating benchtop NMR within the analysis pathway [73]. Novel algorithms and analytical routines are being developed to treat the common SNR problems associated with LF instrumentations, paving the way to new gains in accuracy. More recently, LF NMR instruments have been employed in the analysis of biofluids, including applications of metabolomics techniques for the identification of diabetes in patient urine samples [12]. In this study, urine was collected from a cohort of type 2 diabetic patients and healthy individuals as controls. The study successfully detected markers of diabetic control such as glucose and acetone, LOQ values for these being $2.8 \mathrm{mmol} . / \mathrm{L}$ and $25 \mu \mathrm{mol} . / \mathrm{L}$, respectively. Whilst demonstrating the application of common metabolomics strategies on data collected from LF NMR instruments, associated biofluid preparation and assay protocols were also presented, and optimised for use with bNMR spectrometers. Further work on the implementation of these compact instruments in the analysis of biofluids should involve large cohort studies to provide more statistically robust evidence for the use of these facilities in metabolomics investigations.

Essentially coupled with the future application to low-field NMR measurements, is the concept of the 'singlet' spin state relaxation $\left(T_{s}\right)$ in NMR as a tool to monitor chemical and biochemical processes.[86] Indeed, it is regularly suggested that $T_{l}$ is the longest relaxation process and will return 


\section{Analytica Chimica Acta 2019}

1 the measurable magnetisation to equilibrium. More recently, however, it has been considered that $T_{s}$

2 can in fact be longer than $T_{1}$. Simple molecules with carefully selected spin-symmetry and often with

3 isotopic enhancement can display $T_{s}$ values of the order of many minutes to approximately 1 hour in

4 the liquid state, with $T_{l}$ values that are considerably shorter.

5 The theory of relaxation processes was described in 1965 by Redfield,[87] and superoperators

6 described in 1982 by Jeener,[88] with the steady-state pulse sequences in 1992,[89] and a master

7 equation of relaxation networks in 1994 by Levitt.[90] Subsequently, application of long-lived singlet

8 states have been reviewed,[91,92] and highlight $T_{s}$ values of up to 1 hour (Figure 6). This opens up

9 the possibility of monitoring reaction processes and metabolism over a much longer time period than

10 what was possible before, using NMR spectroscopy, as well as in-vivo MRI applications using

11 hyperpolarised material, and could indeed lead to further developments in the applications of LF

12 NMR analysis. 
Theory of NMR relaxation $1955-2017$

\begin{tabular}{|c|c|c|}
\hline 1955 & The Theory of Relaxation Process & Redfield \\
\hline 98 & SuperOperators in Magnetic Resonance & Jeener \\
\hline & Steady State Magnetic Resonance Pulse Experiments & Levitt \\
\hline & $\begin{array}{l}\text { The Homogeneous Master Equation } \\
\text { and Manipulation of Relaxation Networks }\end{array}$ & Levitt \\
\hline
\end{tabular}

2004<smiles>Brc1ccsc1Br</smiles>$$
\mathrm{T}_{1}=16.8 \mathrm{~s} \quad \mathrm{~T}_{\mathrm{s}}=104 \mathrm{~s}
$$

2004<smiles>CC(N)Cl</smiles>

$\mathrm{T}_{1}=7.8 \mathrm{~s} \quad \mathrm{Ts}_{\mathrm{s}}=141 \mathrm{~s}$

2008

$\mathrm{N}_{2} \mathrm{O}$

$\mathrm{T}_{1}=2-3 \mathrm{~min} \quad \mathrm{Ts}_{\mathrm{s}}=26 \mathrm{~min}$

2011

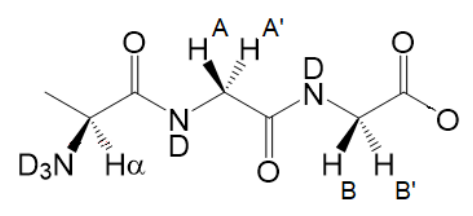

$$
\mathrm{T}_{1}=1 \mathrm{~s}
$$$$
T_{s}=11 \mathrm{~s}
$$

2012

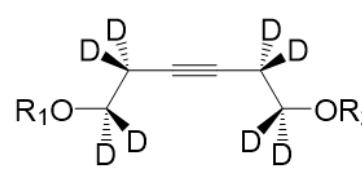<smiles>[R6]C(O)C#CC(O)O</smiles>

$\mathrm{T}_{1}=27 \mathrm{~s}$

$\mathrm{Ts}_{\mathrm{s}}=577 \mathrm{~s}$

2015

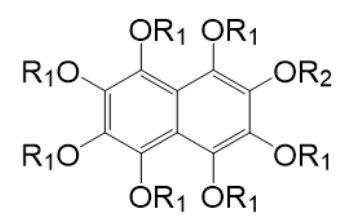

$\mathrm{T}_{1}=1 \mathrm{~min} \quad \mathrm{Ts}_{\mathrm{s}}=1 \mathrm{hour}$

2 Figure 6. Progress in NMR relaxation theory from 1955 to 2017 describing singlet NMR methodology in spin-1/2 systems based on Ref [92].

We may also conclude that cryogen-free benchtop NMR systems do not require a dedicated, customised laboratory space, nor also specialist staff, for their effective operation; no specialist laboratory requirements, maintenance and management are necessary; multinuclear measurements, e.g. ${ }^{1} \mathrm{H},{ }^{13} \mathrm{C}$ and ${ }^{19} \mathrm{~F}$, are possible with a single probe; as with higher field spectrometers; only $0.50 \mathrm{ml}$ of sample is required, and it employs common 5-mm diameter NMR tubes; rapid spectral acquisition and therefore high sample throughputs are achievable; suitability for the on-line monitoring of 


\section{Analytica Chimica Acta 2019}

1 chemical reactions; avoidance of time-consuming and expensive acquisition of spectra on high

2 operating frequency spectrometers (i.e. those $\geq 400 \mathrm{MHz}$ ) via the rapid prior screening of samples in

3 analytical strategies targeted on the removal of those not suitable for this purpose; for some available

4 benchtop facilities, there is no requirement for expensive deuterated NMR solvents; and finally, the

5 technique is therefore highly promising for the 'point-of-care' diagnostic and prognostic screening of

6 biofluids for selected human or animal diseases, in any small laboratory space, directly at non-

7 laboratory health centre clinics (i.e. medical or dental surgeries, or pharmacies), or alternative point-

8 of-contact patient sites. Therefore, the applications of these techniques continue to grow, and will

9 likely develop further into personalised medicine and clinical chemistry-based disease monitoring

10 applications. Analytical parameters relating to articles considered in this study are summarised in

$11 \quad$ Table 6. 
Table 6. Summary of analytical parameters from studies employing LF bNMR spectroscopy, referenced in this review, and ordered by the section of this manuscript in which the reference appears, and study name. Sensitivity expressed as SNR or LOD/Q; number of scans, acquisition time and repetition time are featured where these appear in the text or supplementary information of the relevant manuscripts. Abbreviations: hr. (hours), min. (minutes), and s (seconds). 
Analytica Chimica Acta 2019

\begin{tabular}{|c|c|c|c|c|c|c|}
\hline Section & Study & Analyte/Reaction & $\begin{array}{l}\text { Sensitivity (including } \\
\text { LOD, LOQ, SNR) } \\
\text { (lowest recorded) } \\
\end{array}$ & $\begin{array}{l}\text { Number of } \\
\text { scans or total } \\
\text { acquisition time } \\
\end{array}$ & $\begin{array}{l}\text { Repetition } \\
\text { time }\end{array}$ & Reference \\
\hline \multirow[t]{3}{*}{$\begin{array}{l}\text { Experimental } \\
\text { developments }\end{array}$} & $\begin{array}{l}\text { SABRE } \\
\text { hyperpolarization } \\
\text { enables high- } \\
\text { sensitivity }{ }^{1} \mathrm{H} \text { and }{ }^{13} \mathrm{C} \\
\text { bNMR analysis }\end{array}$ & $\begin{array}{l}\text { Pyridine } \\
\text { 4-Methylpyridine }\end{array}$ & $\begin{array}{l}\text { SABRE methodology } \\
\text { leads to up to } 17,000- \\
\text { fold }{ }^{1} \mathrm{H} \text { and } 75,500 \text {-fold } \\
{ }^{13} \mathrm{C} \text { NMR signal } \\
\text { intensity enhancements }\end{array}$ & $\begin{array}{l}{ }^{1} \mathrm{H}: 256 \\
{ }^{13} \mathrm{C}: 4096\end{array}$ & Not reported & {$[27]$} \\
\hline & $\begin{array}{l}\text { A self-optimizing } \\
\text { synthetic organic } \\
\text { reactor system using } \\
\text { real-time in-line } \\
\text { NMR }\end{array}$ & $\begin{array}{l}\text { Diels-Alder cycloaddition } \\
\text { Cyclopentadiene } \\
\text { Acrolein } \\
\text { Benzylamine }\end{array}$ & Not reported & $\begin{array}{l}{ }^{13} \mathrm{C}: 64 \\
{ }^{1} \mathrm{H} \text { COSY : } 9 \\
\text { min. } \\
\text { HSQC: } \mathbf{3 8} \text { min. }\end{array}$ & $<10 \mathrm{~s}$ & {$[31]$} \\
\hline & $\begin{array}{l}\text { Compact NMR with } \\
\text { lanthanide shift } \\
\text { reagents }\end{array}$ & $\begin{array}{l}\text { Adamantan-2-ol } \\
\text { Europium(III)-tris(1,1,1,2,2,3,4- } \\
\text { heptafluoro-7,7-dimethyl-4,6- } \\
\text { octanedionate }\end{array}$ & Not reported & $\begin{array}{l}{ }^{1} \mathrm{H}: 16 \\
{ }^{19} \mathrm{~F}: 32\end{array}$ & $\begin{array}{l}10 \mathrm{~s} \\
5 \mathrm{~s}\end{array}$ & {$[36]$} \\
\hline $\begin{array}{l}\text { Applications in } \\
\text { materials chemistry }\end{array}$ & $\begin{array}{l}\text { Compact low-field } \\
\text { NMR spectroscopy } \\
\text { and chemometrics: A } \\
\text { tool box for the } \\
\text { quality control of raw } \\
\text { rubber }\end{array}$ & $\begin{array}{l}\text { Styrene } \\
\text { 1,2-Butadiene } \\
\text { cis-1,4-Butadiene } \\
\text { trans-1,4-Butadiene }\end{array}$ & Not reported & $\begin{array}{l}{ }^{1} \mathrm{H}: 4 \\
{ }^{13} \mathrm{C}: 4096(\mathbf{5 . 7} \\
\text { hr.) } \\
{ }^{13} \mathrm{C} \text { DEPT: } 4096 \\
\text { (17 hr.) }\end{array}$ & $15 \mathrm{~s}$ & {$[3]$} \\
\hline $\begin{array}{l}\text { Applications in food } \\
\text { and agricultural } \\
\text { chemistry }\end{array}$ & $\begin{array}{l}\text { Authentication of } \\
\text { beef versus horse } \\
\text { meat using } 60 \mathrm{MHz} \\
{ }^{1} \mathrm{H} \text { NMR } \\
\text { spectroscopy }\end{array}$ & $\begin{array}{l}\text { Beef meat } \\
\text { Horse meat } \\
\text { tristearoylglycerol (C18:0) } \\
\text { trioleoylglycerol (C18:1) } \\
\text { trilinolenoylglycerol }(\mathrm{C} 18: 3) \\
\text { Stock mixture: } 15 \%(\mathrm{w} / \mathrm{w}) \\
\mathrm{C} 18: 0 \text { and } 85 \%(\mathrm{w} / \mathrm{w}) \mathrm{C} 18: 1\end{array}$ & Not reported & $\begin{array}{l}\text { Total acquisition } \\
\text { time was } \\
\text { maintained at } \\
\sim 10 \text { min. }\end{array}$ & $\begin{array}{l}\text { Training set: } \\
30 \mathrm{~s} \\
\text { Test samples: } \\
\text { 2-30 s }\end{array}$ & [49] \\
\hline
\end{tabular}




\begin{tabular}{|c|c|c|c|c|c|}
\hline $\begin{array}{l}60 \mathrm{MHz}{ }^{1} \mathrm{H} \text { NMR } \\
\text { spectroscopy for the } \\
\text { analysis of edible oils }\end{array}$ & $\begin{array}{l}\text { Extra virgin olive oil } \\
\text { Hazelnut oil }\end{array}$ & $\begin{array}{l}\text { Capable of detecting } \\
\text { adulteration of olive oil } \\
\text { with hazelnut oil at } \\
\text { levels }>11 \%(\mathrm{w} / \mathrm{w})\end{array}$ & ${ }^{1} \mathrm{H}: 16$ & Not reported & [50] \\
\hline $\begin{array}{l}\text { High-throughput } \\
\text { authentication of } \\
\text { edible oils with } \\
\text { benchtop Ultrafast } \\
\text { 2D NMR analysis }\end{array}$ & $\begin{array}{l}\text { Olive oil } \\
\text { Hazelnut oil } \\
\text { Sesame oil } \\
\text { Rapeseed oil } \\
\text { Corn oil } \\
\text { Sunflower oil } \\
\end{array}$ & $\begin{array}{l}\text { 1D: Not reported } \\
\text { 2D: }>20: 1\end{array}$ & $\begin{array}{l}\text { 1D: } 16(2.4 \\
\text { min.), dwell- } \\
\text { time: } 200 \mu \mathrm{s} \\
\text { 2D COSY: } 72 \\
\text { (2.4 min.) }\end{array}$ & $\begin{array}{l}\text { 1D: } 15 \mathrm{~s} \\
\text { 2D COSY: } 2 \mathrm{~s}\end{array}$ & [51] \\
\hline $\begin{array}{l}\text { A } 43 \mathrm{MHz} \text { LF } \\
\text { benchtop nuclear } \\
\text { magnetic resonance } \\
\text { method to } \\
\text { discriminate perilla } \\
\text { oil authenticity }\end{array}$ & $\begin{array}{l}\text { Perilla Oil } \\
\text { Linoleoylglycerols } \\
\text { Unsaturated fatty acids } \\
\text { Fatty acids } \\
\text { Glycerol }\end{array}$ & Not reported & ${ }^{1} \mathrm{H}: 32$ (4-5 min.) & $7 \mathrm{~s}$ & [52] \\
\hline $\begin{array}{l}\text { Is LF NMR a } \\
\text { complementary tool } \\
\text { to GC-MS in quality } \\
\text { control of essential } \\
\text { oils? A case study: } \\
\text { patchouli essential oil }\end{array}$ & $\begin{array}{l}\text { Patchouli oil (13 varieties) } \\
\text { Amyris oil } \\
\text { Benzyl alcohol } \\
\text { Benzyl benzoate } \\
\text { Cedar wood oil } \\
\text { Copaiva balsam } \\
\text { Diethyl phthalate } \\
\text { Dioctyl phthalate } \\
\text { Gurjun balsam } \\
\text { Hercolyn } \\
\text { Isobornyl acetate } \\
\text { Methyl benzoate } \\
\text { Paraffin } \\
\text { Paraffin viscid } \\
\text { Pepper oil } \\
\text { Propyleneglycol } \\
\text { Ricinus oil }\end{array}$ & $\begin{array}{l}\text { LOD = Patchouli oil } \\
13 \%(w / w)\end{array}$ & ${ }^{1} \mathrm{H}: 32$ & $4 \mathrm{~s}$ & [53] \\
\hline
\end{tabular}


Analytica Chimica Acta 2019

\begin{tabular}{|c|c|c|c|c|c|c|}
\hline & \multicolumn{6}{|c|}{$\begin{array}{l}\text { Vetiver oil } \\
1 \mathrm{R}-(-) \text { myretenol }\end{array}$} \\
\hline & $\begin{array}{l}\text { Fast Sampling, } \\
\text { Analyses and } \\
\text { Chemometrics for } \\
\text { Plant Breeding: Bitter } \\
\text { Acids, Xanthohumol } \\
\text { and Terpenes in } \\
\text { Lupulin Glands of } \\
\text { Hops }\end{array}$ & $\begin{array}{l}\text { Lupulin gland extracts } \\
\text { Cohumulone } \\
\text { Colupulone } \\
\text { mixture of Humulone and } \\
\text { Adhumulone } \\
\text { mixture of Lupulone and } \\
\text { Adlupulone } \\
\text { Xanthohumol } \\
\text { Myrcene } \\
\text { Humulene } \\
\text { Caryophyllene } \\
\beta \text {-Farnesene } \\
\text { Aromadendrene } \\
\alpha \text { - and } \beta \text {-Selinene } \\
\text { Germacrene B }\end{array}$ & $\begin{array}{l}\text { Cohumulone signal not } \\
\text { resolved from that of } \\
\text { Adhumulone at } 43 \mathrm{MHz}\end{array}$ & ${ }^{1} \mathrm{H}: 60$ & $20 \mathrm{~s}$ & [56] \\
\hline
\end{tabular}




\begin{tabular}{|c|c|c|c|c|c|}
\hline $\begin{array}{l}\text { Continuous-flow } \\
\text { synthesis of fluorine- } \\
\text { containing fine } \\
\text { chemicals with } \\
\text { integrated bNMR } \\
\text { analysis }\end{array}$ & $\begin{array}{l}\text { Krapcho decarboxylation; } \\
\text { Ruppert-Prakash } \\
\text { perfluoroalkylation of } \\
\text { benzaldehyde; } \\
\text { Dye-sensitised visible light C- } \\
\text { H arylation. } \\
\text { Benzaldehyde in THF; } \\
{\mathrm{TMS}-\mathrm{CF}_{3} ;} \text {; } \\
\mathrm{TMS}_{2} \mathrm{C}_{5} \text {; } \\
\text { 3-(Trifluoromethyl)phenyl } \\
\text { diazonium tetrafluoroborate; } \\
\text { Eosin Y; } \\
\text { 4-(Trifluoromethyl) benzyl } \\
\text { alcohol }\end{array}$ & $\begin{array}{l}\text { Lowest recorded SNR = } \\
4.9: 1 \text { at a concentration } \\
\text { of } 0.15 \text { mol. } \mathrm{dm}^{-3} \text { and a } \\
\text { flow rate of } 4.0 \mathrm{~mL} \\
\mathrm{~min}^{-1} \text {. SNR }>20 \text { is } \\
\text { achieved for higher } \\
\text { numbers of scans }(>4) \\
\text { and concentrations, and } \\
\text { lower flow-rates. }\end{array}$ & ${ }^{19} \mathrm{~F}: 4,8,16,64$ & $2 \mathrm{~s}$ & [59] \\
\hline $\begin{array}{l}\text { Process spectroscopy } \\
\text { in microemulsions- } \\
\text { setup and multi- } \\
\text { spectral approach for } \\
\text { reaction monitoring } \\
\text { of a homogeneous } \\
\text { hydroformylation } \\
\text { process }\end{array}$ & $\begin{array}{l}\text { Hydroformylation reaction: } \\
\text { 1-Dodecene; } \\
\text { To Dridecanal; } \\
\text { Catalysed by: } \\
\text { Rh coordination complex with } \\
\text { SulfoXantPhos ligand }\end{array}$ & Not reported & $\begin{array}{l}\text { Reaction } \\
\text { monitoring: } 1 \\
\text { spectrum per } \\
\text { min. }\end{array}$ & $\mathrm{n} / \mathrm{a}$ & [61] \\
\hline $\begin{array}{l}\text { Online LF NMR } \\
\text { spectroscopy for } \\
\text { process control of an } \\
\text { industrial lithiation }\end{array}$ & $\begin{array}{l}\text { Aniline } \\
\text { 1-Fluoro-2 nitrobezene } \\
\text { 2-Nitrodiphenylamine } \\
\text { Lithium bis(trimethylsilyl) }\end{array}$ & Not reported & 1 scan & $15 \mathrm{~s}$ & {$[62]$} \\
\hline
\end{tabular}


Analytica Chimica Acta 2019

\begin{tabular}{|c|c|c|c|c|c|}
\hline $\begin{array}{l}\text { reaction-automated } \\
\text { data analysis }\end{array}$ & amide & & & & \\
\hline $\begin{array}{l}\text { A bNMR } \\
\text { spectrometer as a tool } \\
\text { for monitoring } \\
\text { mesoscale } \\
\text { continuous-flow } \\
\text { organic synthesis: } \\
\text { equipment interface } \\
\text { and assessment in } \\
\text { four organic } \\
\text { transformations }\end{array}$ & $\begin{array}{l}\text { Acid-catalysed esterification } \\
\text { Acetic acid } \\
\text { Sulfuric acid } \\
\text { Base-catalysed Knoevenagel } \\
\text { condensation } \\
\text { Benzaldehyde/Ethyl } \\
\text { Acetoacetate } \\
\text { Diels-Alder reaction } \\
\text { Piperdine } \\
\text { Maleic anhydride } \\
\text { Isoprene } \\
\text { Alkylation reaction } \\
\text { Salicylaldehyde/DBU } \\
\text { 1-Bromobutane } \\
\end{array}$ & Not reported & 10 scans & $9 \mathrm{~s}$ & [65] \\
\hline $\begin{array}{l}\text { Medium Resolution } \\
{ }^{1} \mathrm{H} \text { NMR at } 62 \mathrm{MHz} \\
\text { as a new chemically } \\
\text { sensitive online } \\
\text { detector for size- } \\
\text { exclusion } \\
\text { chromatography } \\
\text { (SEC-NMR) }\end{array}$ & $\begin{array}{l}\text { Polystyrene } \\
\text { Polymethylmethacrylate }\end{array}$ & $\begin{array}{l}\text { From } 27: 1\left(-\mathrm{CH}_{2}-\right) \text { to } \\
\text { 110:1 }\left(\mathrm{OCC}_{3}\right) \text { for } \\
\text { Polymethylmethacrylate }\end{array}$ & ${ }^{1} \mathrm{H}: 128$ & $0.5 \mathrm{~s}$ & [67] \\
\hline $\begin{array}{l}\text { Desktop NMR } \\
\text { spectroscopy for real- } \\
\text { time monitoring of an } \\
\text { acetalization reaction } \\
\text { in comparison with } \\
\text { gas chromatography } \\
\text { and NMR at } 9.4 \mathrm{~T}\end{array}$ & $\begin{array}{l}\text { Acetalization } \\
\text { Ethylene glycol } \\
p \text {-Nitrobenzaldehyde } \\
p \text {-Toluenesulphonic acid } \\
\text { 2-(4-Nitrophenyl)-1, 3- } \\
\text { dioxolane }\end{array}$ & Not reported & ${ }^{1} \mathrm{H}: 1$ & $15 \mathrm{~s}$ & [70] \\
\hline
\end{tabular}


Analytica Chimica Acta 2019

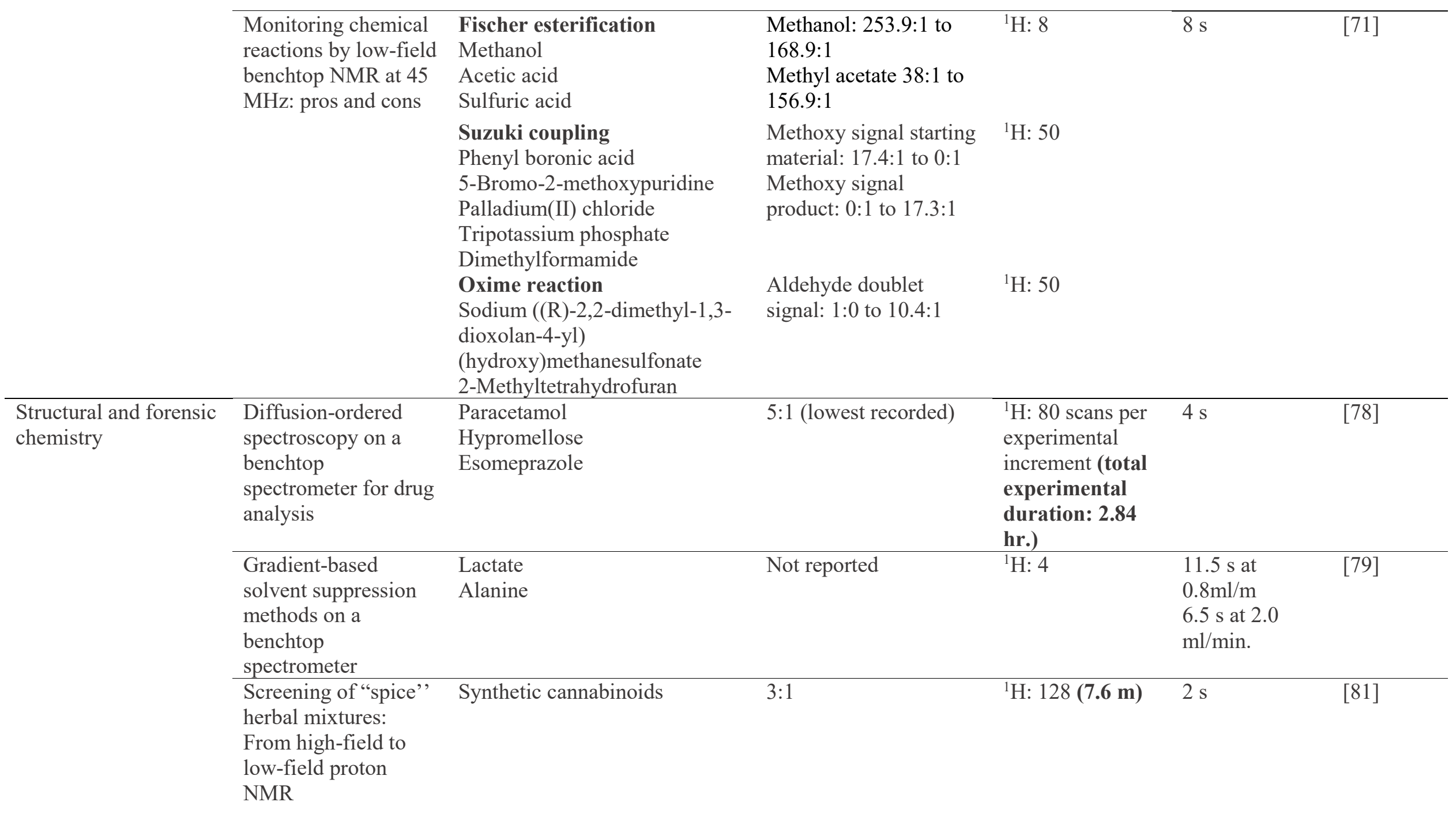




\begin{tabular}{|c|c|c|c|c|}
\hline $\begin{array}{l}\text { Desktop NMR for } \\
\text { structure elucidation } \\
\text { and identification of } \\
\text { strychnine } \\
\text { adulteration }\end{array}$ & $\begin{array}{l}\text { Strychnine hydrochloride } \\
\text { (SHY) }\end{array}$ & Not reported & $\begin{array}{l}{ }^{1} \mathrm{H}: \mathrm{S} 4 \\
{ }^{1} \mathrm{H} \text { SHY: } 64 \\
{ }^{1} \mathrm{H} \text { SHE: } 4 \\
{ }^{13} \mathrm{C}: 4096 \\
\text { 2D COSY: } 4 \\
\text { 2D HETCOR: } \\
\text { 128 } \\
\text { 2D HSQC: } 64 \\
\text { 2D HMBC: } 64 \\
\text { 2D J-r: } 4\end{array}$ & $\begin{array}{l}{ }^{13} \mathrm{C}: 5 \mathrm{~s} \\
\text { 2D COSY:2.2 } \\
\mathrm{s} \\
\text { 2D HETCOR: } \\
10 \mathrm{~s} \\
\text { 2D HSQC: } \\
10 \mathrm{~s} \\
2 \mathrm{D} \mathrm{HMBC}: \\
10 \mathrm{~s} \\
2 \mathrm{D} \mathrm{J} \text {-resolved: } \\
2 \mathrm{~s}\end{array}$ \\
\hline $\begin{array}{l}\text { LF bNMR } \\
\text { Spectroscopy as a } \\
\text { Potential Tool for } \\
\text { Point-of-Care } \\
\text { Diagnostics of } \\
\text { Metabolic } \\
\text { Conditions: } \\
\text { Validation and } \\
\text { Protocols }\end{array}$ & $\begin{array}{l}\text { Glucose } \\
\text { Acetone } \\
\geq 15 \text { further metabolites } \\
\text { simultaneously detectable. }\end{array}$ & $\begin{array}{l}11: 1 \\
>10: 1\end{array}$ & ${ }^{1} \mathrm{H}: 64$ & $10 \mathrm{~s}, 15 \mathrm{~s}$ \\
\hline
\end{tabular}




\section{Analytica Chimica Acta 2019}

\section{References}

2

3 [1] F. Castellani, B. van Rossum, A. Diehl, M. Schubert, K. Rehbein, H. Oschkinat, Structure of a 4 5 protein determined by solid-state magic-angle-spinning NMR spectroscopy, Nature. 420 (2002) 98 .

[2] M. Donaldson, D. Freed, S. Mandal, Y.-Q.Q. Song, Chemical analysis using low-field magnetic resonance, TrAC - Trends Anal. Chem. 83 (2016) 84-93. doi:10.1016/j.trac.2016.03.008.

[3] K. Singh, B. Blümich, Compact low-field NMR spectroscopy and chemometrics: A tool box for quality control of raw rubber, Polymer (Guildf). 141 (2018) 154-165. doi:10.1016/J.POLYMER.2018.02.057.

[4] M. Kumada, T. Fujisawa, Y. Hirao, M. Endo, M. Aoki, T. Kohda, I. Bolshakova, R. Holyaka, Development of 4 tesla permanent magnet, in: PACS2001. Proc. 2001 Part. Accel. Conf. (Cat. No.01CH37268), IEEE, n.d.: pp. 3221-3223. doi:10.1109/PAC.2001.988064.

[5] P. Blümler, F. Casanova, Chapter 5. Hardware Developments: Halbach Magnet Arrays, in: M. L. Johns, E. O. Fridjonsson, S. J. Vogt, A. Haber (Eds.) Mobile NMR and MRI: Developments and Applications, 2016: pp. 133-157. doi:10.1039/9781782628095-00133.

[6] M. Edgar, Physical methods and techniques: NMR spectroscopy, Annu. Reports Sect. "B" (Organic Chem. 109 (2013) 256). doi:10.1039/c3oc90012f.

[7] K. Halbach, Some eddy current effects in solid core magnets, Nucl. Instruments Methods. 107 (1973) 529-540. doi:10.1016/0029-554X(73)90388-1.

[8] D.I. Hoult, R.E. Richards, The signal-to-noise ratio of the nuclear magnetic resonance experiment., J Magn Reson. 24 (1976) 71-85. doi:http://dx.doi.org/10.1016/00222364(76)90233-X.

[9] E. Danieli, J. Perlo, B. Blümich, F. Casanova, Small magnets for portable NMR spectrometers, 


\section{Analytica Chimica Acta 2019}

Angew. Chemie - Int. Ed. 49 (2010) 4133-4135. doi:10.1002/anie.201000221.

[10] B. Blümich, F. Casanova, M. Dabrowski, E. Danieli, L. Evertz, A. Haber, M. Van Landeghem, S. Haber-Pohlmeier, A. Olaru, J. Perlo, O. Sucre, Small-scale instrumentation for nuclear magnetic resonance of porous media, New J. Phys. 13 (2011) 015003. doi:10.1088/13672630/13/1/015003.

[11] D.S. Wishart, Quantitative metabolomics using NMR, TrAC - Trends Anal. Chem. 27 (2008) 228-237. doi:10.1016/j.trac.2007.12.001.

[12] B.C. Percival, Y. Osman, M. Grootveld, M. Gibson, M. Molinari, F. Jafari, M. Martin, F. Casanova, M.L. Mather, M. Edgar, P.B. Wilson, Y. Osman, M. Molinari, F. Jafari, T. Sahota, M. Martin, F. Casanova, M.L. Mather, M. Edgar, J. Masania, P.B. Wilson, M. Grootveld, M. Gibson, M. Molinari, F. Jafari, M. Martin, F. Casanova, M.L. Mather, M. Edgar, P.B. Wilson, Low-Field, Benchtop NMR Spectroscopy as a Potential Tool for Point-of-Care Diagnostics of Metabolic Conditions: Validation, Protocols and Computational Models, High-Throughput. 8 (2018) 2. doi:10.3390/ht8010002.

[13] B. Blümich, Introduction to compact NMR: A review of methods, TrAC - Trends Anal. Chem. 83 (2016) 2-11. doi:10.1016/j.trac.2015.12.012.

[14] K. Singh, B. Blümich, NMR spectroscopy with compact instruments, TrAC - Trends Anal. Chem. 83 (2016) 12-26. doi:10.1016/j.trac.2016.02.014.

[15] B. Blümich, K. Singh, Desktop NMR and Its Applications From Materials Science To Organic Chemistry, Angew. Chemie Int. Ed. 57 (2017) 6996-7010. doi:10.1002/anie.201707084.

[16] A.G. Webb, S.C. Grant, Signal-to-noise and magnetic susceptibility trade-offs in solenoidal microcoils for NMR, J. Magn. Reson. Ser. B. 1 (1996) 83-87.

[17] P.T. Callaghan, Principles of nuclear magnetic resonance microscopy, Oxford University Press, Oxford, 1993.

[18] Z.X. Luo, L. Fox, M. Cummings, T.J. Lowery, E. Daviso, New frontiers in in vitro medical 


\section{Analytica Chimica Acta 2019}

diagnostics by low field T2 magnetic resonance relaxometry, TrAC - Trends Anal. Chem. 83 (2016) 94-102. doi:10.1016/j.trac.2016.02.025.

[19] J.H. Lee, Y. Okuno, S. Cavagnero, Sensitivity enhancement in solution NMR: Emerging ideas and new frontiers, J. Magn. Reson. 241 (2014) 18-31. doi:10.1016/j.jmr.2014.01.005.

[20] C. Hundshammer, S. Düwel, D. Ruseckas, G. Topping, P. Dzien, C. Müller, B. Feuerecker, J.B. Hövener, A. Haase, M. Schwaiger, S.J. Glaser, F. Schilling, Hyperpolarized Amino Acid Derivatives as Multivalent Magnetic Resonance pH Sensor Molecules, Sensors. 18 (2018) 600. doi:10.3390/s18020600.

[21] C.P. Slichter, The discovery and demonstration of dynamic nuclear polarization - a personal and historical account, Phys. Chem. Chem. Phys. 12 (2010) 5741-5751.

[22] E. Kubala, K.A. Muñoz-Álvarez, G. Topping, C. Hundshammer, B. Feuerecker, P.A. Gómez, G. Pariani, F. Schilling, S.J. Glaser, R.F. Schulte, M.I. Menzel, M. Schwaiger, Hyperpolarized 13C Metabolic Magnetic Resonance Spectroscopy and Imaging, JoVE. (2016) e54751.

[23] V.Z. Miloushev, V. Di Gialleonardo, L. Salamanca-Cardona, F. Correa, K.L. Granlund, K.R. Keshari, Hyperpolarized 13C pyruvate mouse brain metabolism with absorptive-mode EPSI at 1 T, J. Magn. Reson. 275 (2017) 120-126. doi:10.1016/J.JMR.2016.12.009.

[24] B. Gizatullin, O. Neudert, S. Stapf, C. Mattea, Dynamic Nuclear Polarization Fast Field Cycling Method for the Selective Study of Molecular Dynamics in Block Copolymers, ChemPhysChem. 18 (2017) 2347-2356. doi:10.1002/cphc.201700539.

[25] S. Lehmkuhl, M. Wiese, L. Schubert, M. Held, M. Küppers, M. Wessling, B. Blümich, Continuous hyperpolarization with parahydrogen in a membrane reactor, J. Magn. Reson. 291 (2018) 8-13. doi:10.1016/J.JMR.2018.03.012.

[26] M.E. Halse, Perspectives for hyperpolarisation in compact NMR, TrAC - Trends Anal. Chem. 83 (2016) 76-83. doi:10.1016/j.trac.2016.05.004.

[27] P.M. Richardson, A.J. Parrott, O. Semenova, A. Nordon, S.B. Duckett, M.E. Halse, SABRE 


\section{Analytica Chimica Acta 2019}

hyperpolarization enables high-sensitivity $1 \mathrm{H}$ and $13 \mathrm{C}$ benchtop NMR spectroscopy, Analyst. 143 (2018), 3442-3450.

[28] J.F.P. Colell, A.W.J. Logan, Z. Zhou, R. V. Shchepin, D.A. Barskiy, G.X. Ortiz, Q. Wang, S.J. Malcolmson, E.Y. Chekmenev, W.S. Warren, T. Theis, Generalizing, Extending, and Maximizing Nitrogen-15 Hyperpolarization Induced by Parahydrogen in Reversible Exchange, J. Phys. Chem. C. 121 (2017) 6626-6634. doi:10.1021/acs.jpcc.6b12097.

[29] M.L. Hirsch, N. Kalechofsky, A. Belzer, M. Rosay, J.G. Kempf, Brute-Force Hyperpolarization for NMR and MRI, J. Am. Chem. Soc. 137 (2015) 8428-8434. doi:10.1021/jacs.5b01252.

[30] D.A. Barskiy, K. V. Kovtunov, E.Y. Gerasimov, M.A. Phipps, O.G. Salnikov, A.M. Coffey, L.M. Kovtunova, I.P. Prosvirin, V.I. Bukhtiyarov, I. V. Koptyug, E.Y. Chekmenev, 2D Mapping of NMR Signal Enhancement and Relaxation for Heterogeneously Hyperpolarized Propane Gas, J. Phys. Chem. C. 121 (2017) 10038-10046. doi:10.1021/acs.jpcc.7b02506.

[31] V. Sans, L. Porwol, V. Dragone, L. Cronin, A self optimizing synthetic organic reactor system using real-time in-line NMR spectroscopy, Chem. Sci. 6 (2015) 1258-1264. doi:10.1039/C4SC03075C.

[32] B. Gouilleux, B.B. Charrier, E. Danieli, J.-N. Dumez, S. Akoka, F.-X.F.-X. Felpin, M. Rodriguez-Zubiri, P. Giraudeau, Real-time reaction monitoring by ultrafast 2D NMR on a benchtop spectrometer, Analyst. 140 (2015) 7854-7858. doi:10.1039/c5an01998b.

[33] Y. Matviychuk, E. von Harbou, D.J. Holland, An experimental validation of a Bayesian model for quantification in NMR spectroscopy, J. Magn. Reson. 285 (2017) 86-100. doi:10.1016/J.JMR.2017.10.009.

[34] M.A.R. Anjum, P.A. Dmochowski, P.D. Teal, A subband Steiglitz-McBride algorithm for automatic analysis of FID data, Magn. Reson. Chem. (2018). doi:10.1002/mrc.4723.

[35] M. Sawall, E. von Harbou, A. Moog, R. Behrens, H. Schröder, J. Simoneau, E. Steimers, K. 


\section{Analytica Chimica Acta 2019}

Neymeyr, Multi-objective optimization for an automated and simultaneous phase and baseline correction of NMR spectral data, J. Magn. Reson. 289 (2018) 132-141. doi:10.1016/J.JMR.2018.02.012.

[36] K. Singh, B. Blümich, Compact NMR Spectroscopy with Shift Reagents, Appl. Magn. Reson. 47 (2016) 1135-1146. doi:10.1007/s00723-016-0821-5.

[37] K. Kazimierczuk, V. Orekhov, Non-uniform sampling: post-Fourier era of NMR data collection and processing, Magn. Reson. Chem. 53 (2015) 921-926. doi:10.1002/mrc.4284.

[38] H. Todt, G. Guthausen, W. Burk, D. Schmalbein, A. Kamlowski, Water/moisture and fat analysis by time-domain NMR, Food Chem. 96 (2006) 436-440.

[39] A. Nordon, C.A. McGill, D. Littlejohn, Process NMR spectrometry, Analyst. 126 (2001) 260272.

[40] K. Schaeler, M. Roos, P. Micke, Y. Golitsyn, A. Seidlitz, T. Thurn-Albrecht, H. Schneider, G. Hempel, K. Saalwaechter, Basic principles of static proton low-resolution spin diffusion NMR in nanophase-separated materials with mobility contrast, Solid State Nucl. Magn. Reson. 72 (2015) 50-63. doi:10.1016/j.ssnmr.2015.09.001.

[41] A. Joos, N. Löwa, F. Wiekhorst, B. Gleich, A. Haase, Size-dependent MR relaxivities of magnetic nanoparticles, J. Magn. Magn. Mater. 427 (2017) 122-126. doi:10.1016/J.JMMM.2016.11.021.

[42] L.R. Stingaciu, A. Pohlmeier, P. Blümler, L. Weihermüller, D. van Dusschoten, S. Stapf, H. Vereecken, Characterization of unsaturated porous media by high-field and low-field NMR relaxometry, Water Resour. Res. 45 (2009) W08412. doi:10.1029/2008WR007459.

[43] C. Horch, S. Schlayer, F. Stallmach, High-pressure low-field 1H NMR relaxometry in nanoporous materials, J. Magn. Reson. 240 (2014) 24-33. doi:10.1016/J.JMR.2014.01.002.

[44] D. Budker, M. Romalis, Optical magnetometry, Nat. Phys. 3 (2007) 227-234. doi:10.1038/nphys566. 


\section{Analytica Chimica Acta 2019}

1 [45] J.P. King, P.J. Coles, J.A. Reimer, Optical polarization of ${ }^{13} \mathrm{C}$ nuclei in diamond through nitrogen vacancy centers, Phys. Rev. B. 81 (2010) 073201. doi:10.1103/PhysRevB.81.073201.

[46] Y.-Q. Song, Magnetic Resonance of Porous Media (MRPM): A perspective, J. Magn. Reson. 229 (2013) 12-24. doi:10.1016/J.JMR.2012.11.010.

[47] D. Capitani, A.P. Sobolev, V. Di Tullio, L. Mannina, N. Proietti, Portable NMR in food analysis, Chem. Biol. Technol. Agric. 4 (2017) 17. doi:10.1186/s40538-017-0100-1.

[48] G. Guthausen, Analysis of food and emulsions, TrAC - Trends Anal. Chem. 83 (2016) 103106. doi:10.1016/j.trac.2016.02.011.

[49] W. Jakes, A. Gerdova, M. Defernez, A.D. Watson, C. McCallum, E. Limer, I.J. Colquhoun, D.C. Williamson, E.K. Kemsley, Authentication of beef versus horse meat using $60 \mathrm{MHz} 1 \mathrm{H}$ NMR spectroscopy, Food Chem. 175 (2015) 1-9. doi:10.1016/j.foodchem.2014.11.110.

[50] T. Parker, E. Limer, A.D. Watson, M. Defernez, D. Williamson, E.K. Kemsley, $60 \mathrm{MHz} 1 \mathrm{H}$ NMR spectroscopy for the analysis of edible oils, Trends Anal. Chem. 57 (2014) 147-158. doi:10.1016/j.trac.2014.02.006.

[51] B. Gouilleux, J. Marchand, B. Charrier, G.S.S. Remaud, P. Giraudeau, High-throughput authentication of edible oils with benchtop Ultrafast 2D NMR, FOOD Chem. 244 (2018) 153158. doi:10.1016/j.foodchem.2017.10.016.

[52] J.H. Kim, H.J. Lee, K. Kwon, H.S. Chun, S. Ahn, B.H. Kim, A 43 MHz Low-Field Benchtop 1H Nuclear Magnetic Resonance Method to Discriminate Perilla Oil Authenticity, J. Oleo Sci. 67 (2018) 507-513. doi:10.5650/jos.ess17243.

[53] A. Krause, Y. Wu, R. Tian, T. van Beek, Is Low-field NMR a Complementary Tool to GC-MS in Quality Control of Essential Oils? A Case Study: Patchouli Essential Oil, Planta Med. (2018). doi:10.1055/a-0605-3967.

[54] M. Grootveld, V.R. Rodado, C.J.L. Silwood, Detection, monitoring, and deleterious health effects of lipid oxidation products generated in culinary oils during thermal stressing episodes, 


\section{Analytica Chimica Acta 2019}

Int. News Fats, Oils Relat. Mater. (2014). doi:10.1017/CBO9781107415324.004.

[55] M.H.M. Killner, E. Danieli, F. Casanova, J.J.R. Rohwedder, B. Blümich, Mobile compact 1H NMR spectrometer promises fast quality control of diesel fuel, Fuel. 203 (2017) 171-178. doi:10.1016/J.FUEL.2017.04.081.

[56] D.P. Killeen, O.C. Watkins, C.E. Sansom, D.H. Andersen, K.C. Gordon, N.B. Perry, Fast Sampling, Analyses and Chemometrics for Plant Breeding: Bitter Acids, Xanthohumol and Terpenes in Lupulin Glands of Hops ( Humulus lupulus ), Phytochem. Anal. 28 (2017) 50-57. doi:10.1002/pca.2642.

[57] J. Masania, M. Grootveld, P. B.Wilson, Teaching Analytical Chemistry to Pharmacy Students: A Combined, Iterative Approach. Journal of Chemical Education, 95 (2017) 47-54.

[58] B. Ahmed-Omer, E. Sliwinski, J.P. Cerroti, S. V Ley, Continuous processing and efficient in situ reaction monitoring of a hypervalent iodine (III) mediated cyclopropanation using benchtop NMR spectroscopy, Org. Process Res. Dev. 20 (2016) 1603-1614.

[59] T.H. Rehm, C. Hofmann, D. Reinhard, H.-J. Kost, P. Löb, M. Besold, K. Welzel, J. Barten, A. Didenko, D. V. Sevenard, B. Lix, A.R. Hillson, S.D. Riegel, Continuous-flow synthesis of fluorine-containing fine chemicals with integrated benchtop NMR analysis, React. Chem. Eng. 2 (2017) 315-323. doi:10.1039/C7RE00023E.

[60] D. Cortés-Borda, E. Wimmer, B. Gouilleux, E. Barré, N. Oger, L. Goulamaly, L. Peault, B. Charrier, C. Truchet, P. Giraudeau, M. Rodriguez-Zubiri, E. Le Grognec, F.-X. Felpin, An Autonomous Self-Optimizing Flow Reactor for the Synthesis of Natural Product Carpanone, J. Org. Chem. (2018). doi:10.1021/acs.joc.8b01821.

[61] K. Meyer, J.-P. Ruiken, M. Illner, A. Paul, D. Mueller, E. Esche, G. Wozny, M. Maiwald, D. Müller, E. Esche, G. Wozny, M. Maiwald, Process spectroscopy in microemulsions-setup and multi-spectral approach for reaction monitoring of a homogeneous hydroformylation process, Meas. Sci. Technol. 28 (2017) 035501. doi:10.1088/1361-6501/aa54f3. 


\section{Analytica Chimica Acta 2019}

1 [62] S. Kern, K. Meyer, S. Guhl, P. Gräßer, A. Paul, R. King, M. Maiwald, Online low-field NMR spectroscopy for process control of an industrial lithiation reaction - automated data analysis, Anal. Bioanal. Chem. 410 (2018) 3349-3360. doi:10.1007/s00216-018-1020-z.

[63] B. Picard, B. Gouilleux, T. Lebleu, J. Maddaluno, I. Chataigner, M. Penhoat, F.-X. Felpin, P. Giraudeau, J. Legros, Oxidative Neutralization of Mustard-Gas Simulants in an On-Board Flow Device with In-Line NMR Monitoring, Angew. Chemie Int. Ed. 56 (2017) 7568-7572. doi:10.1002/anie.201702744.

[64] H. Kim, Y. Yonekura, J. Yoshida, A Catalyst-Free Amination of Functional Organolithium Reagents by Flow Chemistry, Angew. Chemie Int. Ed. 57 (2018) 4063-4066. doi:10.1002/anie.201713031.

[65] C.M. Archambault, N.E. Leadbeater, A benchtop NMR spectrometer as a tool for monitoring mesoscale continuous-flow organic synthesis: equipment interface and assessment in four organic transformations, RSC Adv. 6 (2016) 101171-101177. doi:10.1039/c6ra19662d.

[66] K. Singh, B. Blümich, Desktop NMR for structure elucidation and identification of strychnine adulteration, Analyst. 142 (2017) 1459-1470. doi:10.1039/C7AN00020K.

[67] J. Höpfner, K.-F. Ratzsch, C. Botha, M. Wilhelm, Medium Resolution ${ }^{1}$ H-NMR at $62 \mathrm{MHz}$ as a New Chemically Sensitive Online Detector for Size-Exclusion Chromatography (SECNMR), Macromol. Rapid Commun. 39 (2018) 1700766. doi:10.1002/marc.201700766.

[68] F. Daliltz, M. Cudaj, M. Maiwald, G. Guthausen, Process and reaction monitoring by low-field NMR spectroscopy, Prog. Nucl. Magn Reson. Spectrosc. 60 (2012) 52-70.

[69] M.V. Gomez, A. de la Hoz, NMR reaction monitoring in flow synthesis, Beilstein J. Org. Chem. 13 (2017) 285-300. doi:10.3762/bjoc.13.31.

[70] K. Singh, E. Danieli, B. Blümich, Desktop NMR spectroscopy for real-time monitoring of an acetalization reaction in comparison with gas chromatography and NMR at 9.4 T, Anal. Bioanal. Chem. 409 (2017) 7223-7234. doi:10.1007/s00216-017-0686-y. 


\section{Analytica Chimica Acta 2019}

1 [71] M.V.S. Elipe, R.R. Milburn, M.V. Silva Elipe, R.R. Milburn, Monitoring chemical reactions by low-field benchtop NMR at 45MHz: pros and cons, Magn. Reson. Chem. 54 (2016) 437443. doi:10.1002/mrc.4189.

[72] V. Räntzsch, M. Wilhelm, G. Guthausen, Hyphenated low-field NMR techniques: combining NMR with NIR, GPC/SEC and rheometry, Magn. Reson. Chem. 54 (2016) 494-501. doi:10.1002/mrc.4219.

[73] J.M. Granda, L. Donina, V. Dragone, D.-L. Long, L. Cronin, Controlling an organic synthesis robot with machine learning to search for new reactivity, Nature. 559 (2018) 377-381. doi:10.1038/s41586-018-0307-8.

[74] C.G. Fraga, G.A. Pérez Acosta, M.D. Crenshaw, K. Wallace, G.M. Mong, H.A. Colburn, Impurity Profiling to Match a Nerve Agent to Its Precursor Source for Chemical Forensics Applications, Anal. Chem. 83 (2011) 9564-9572. doi:10.1021/ac202340u.

[75] J.L. Bonjour, A.L. Hass, D.W. Pollock, A. Huebner, J.A. Frost, Bringing NMR and IR Spectroscopy to High Schools, J. Chem. Educ. 94 (2017) 38-43. doi:10.1021/acs.jchemed.6b00406.

[76] A. Wilson, C. Myers, G. Crull, M. Curtis, P. Pasciak Patterson, Analysis of Soft Drinks Using Nuclear Magnetic Resonance Spectroscopy: A Mentorship, J. Chem. Educ. 76 (1999) 1414. doi:10.1021/ed076p1414.

[77] B. Bogun, S. Moore, $1 \mathrm{H}$ and 31P benchtop NMR of liquids and solids used in and/or produced during the manufacture of methamphetamine by the HI reduction of pseudoephedrine/ephedrine, Forensic Sci. Int. 278 (2017) 68-77. doi:10.1016/J.FORSCIINT.2017.06.026.

[78] G. Assemat, B. Gouilleux, D. Bouillaud, J. Farjon, V. Gilard, P. Giraudeau, M. Malet-Martino, Diffusion-ordered spectroscopy on a benchtop spectrometer for drug analysis, J. Pharm. Biomed. Anal. 160 (2018) 268-275. doi:10.1016/J.JPBA.2018.08.011. 


\section{Analytica Chimica Acta 2019}

1 [79] B. Gouilleux, B. Charrier, S. Akoka, P. Giraudeau, Gradient-based solvent suppression methods on a benchtop spectrometer, Magn. Reson. Chem. 55 (2017) 91-98. doi:10.1002/mrc.4493.

[80] C.P. Butts, C.R. Jones, E.C. Towers, J.L. Flynn, L. Appleby, N.J. Barron, Interproton distance determinations by NOE - surprising accuracy and precision in a rigid organic molecule, Org. Biomol. Chem. 9 (2011) 177-184. doi:10.1039/C0OB00479K.

[81] G. Assemat, F. Dubocq, S. Balayssac, C. Lamoureux, M. Malet-Martino, V. Gilard, Screening of "spice" herbal mixtures: From high-field to low-field proton NMR, FORENSIC Sci. Int. 279 (2017) 88-95. doi:10.1016/j.forsciint.2017.08.006.

[82] R.M. Salek, M.L. Maguire, E. Bentley, D. V. Rubtsov, T. Hough, M. Cheeseman, D. Nunez, B.C. Sweatman, J.N. Haselden, R.D. Cox, S.C. Connor, J.L. Griffin, A metabolomic comparison of urinary changes in type 2 diabetes in mouse, rat, and human, Physiol. Genomics. (2007). doi:10.1152/physiolgenomics.00194.2006.

[83] D.S. Wishart, Y.D. Feunang, A. Marcu, A.C. Guo, K. Liang, R. Vázquez-Fresno, T. Sajed, D. Johnson, C. Li, N. Karu, Z. Sayeeda, E. Lo, N. Assempour, M. Berjanskii, S. Singhal, D. Arndt, Y. Liang, H. Badran, J. Grant, A. Serra-Cayuela, Y. Liu, R. Mandal, V. Neveu, A. Pon, C. Knox, M. Wilson, C. Manach, A. Scalbert, HMDB 4.0: The human metabolome database for 2018, Nucleic Acids Res. (2018). doi:10.1093/nar/gkx1089.

[84] D.P. Cistola, M.D. Robinson, Compact NMR relaxometry of human blood and blood components, TrAC - Trends Anal. Chem. 83 (2016) 53-64. doi:10.1016/j.trac.2016.04.020.

[85] H. Lee, E. Sun, D. Ham, R. Weissleder, Chip-NMR biosensor for detection and molecular analysis of cells, Nat. Med. 14 (2008) 869-874. doi:10.1038/nm.1711.

[86] R. Sarkar, P.R. Vasos, G. Bodenhausen, Singlet-State Exchange NMR Spectroscopy for the Study of Very Slow Dynamic Processes, J. Am. Chem. Soc. 129 (2007) 328-334. doi:10.1021/ja0647396. 


\section{Analytica Chimica Acta 2019}

1 [87] A.G. Redfield, AG Redfield, Adv. Magn. Reson. 1, 1 (1965)., Adv. Magn. Reson. 1 (1965) 1.

2 [88] J. Jeener, Superoperators in Magnetic Resonance, Adv. Magn. Opt. Reson. 10 (1982) 1-51.

3 [89] M.H. Levitt, L. Di Bari, Steady state in magnetic resonance pulse experiments, Phys. Rev.

4 Lett. 69 (1992) 3124-3127. doi:10.1103/PhysRevLett.69.3124.

5 [90] M.H. Levitt, L. Di Bari, The homogeneous master equation and the manipulation of relaxation 6 networks, Bull. Magn. Reson. 16 (1994) 94.

7 [91] M.H. Levitt, Singlet nuclear magnetic resonance, Annu. Rev. Phys. Chem. 63 (2012) 89-105.

8 [92] G. Pileio, Singlet NMR methodology in two-spin-1/2 systems, Prog. Nucl. Magn. Reson.

9 Spectrosc. 98 (2017) 1-19.

10 